\title{
Assessing subsidence of Mexico City from InSAR and LandSat ETM+ with CGPS and SVM
}

\author{
Davod Poreh ${ }^{1}$, Saied Pirasteh ${ }^{2^{*}}$ (D) and Enrique Cabral-Cano ${ }^{3}$
}

\begin{abstract}
This study presents an enhanced analysis of the subsidence rates and their effects on Mexico City. As a result of excess water withdrawal, Mexico City is experiencing subsidence. We integrated and analyzed Interferometric Synthetic Aperture Radar (InSAR), Continuous Global Positioning Systems (CGPS), and optical remote sensing data to analyze Mexico City's subsidence. This study utilized 52 ENVISAT-ASAR, nine GPS stations, and one Landsat ETM+ image from the Mexico City area to understand better the subsidence rates and their effects on Mexico City's community. The finding of this study reveals a high amount of correlation (up to 0.98) between two independent geodetic methods. We also implemented the Support Vector Machine (SVM) analysis method based on Landsat ETM+ image to classify Mexico City's population density. We used SVM to compare Persistent Scatterer Interferometry (PSI) subsidence rates with the buildings' distribution densities. This integrated study shows that the fastest subsidence zone (i.e., areas greater than $100 \mathrm{~mm} / \mathrm{yr}$ ), which falls into the above-mentioned temporal baseline, occurs in high and moderate building distribution density areas.
\end{abstract}

Keywords: Mexico City, Subsidence, InSAR, GPS, PSI, SVM

\section{Introduction}

Interferometric Synthetic Aperture Radar (InSAR) data have been available for geological and geomorphological analysis since the launching of ERS 1 in 1992. Persistent Scatterer Interferometry (PSI) has been employed for more than 15 years to monitor the surface of the Earth. In the last two decades, PSI and similar techniques have been proposed as well (Usai and Hanssen 1997; Hanssen 2001; Ferretti et al. 2001; Lanari et al. 2004; Salvi et al. 2004; Ferretti et al. 2011; Poreh et al. 2017; Farolfi et al. 2019). Developed by researchers at the Politecnico di Milano (POLIMI), the procedure of the PSI technique is known as Permanent/Persistent Scatterers Interferometry (Ferretti et al. 1999; Wang et al. 2010). Prior to monitoring similar terrain subsidence, several

\footnotetext{
* Correspondence: sapirasteh@swjtu.edu.cn

${ }^{2}$ Department of Surveying and Geoinformatics, Faculty of Geosciences and Environmental Engineering (FGEE), Southwest Jiaotong University, Chengdu 611756, China

Full list of author information is available at the end of the article
}

researchers used geodetic methods such as InSAR, PSI, and Continuous Global Positioning System (CGPS) (Berardino et al. 2002; Mora et al. 2003; Crosetto et al. 2005; Hooper 2008; Crosetto et al. 2008; Pepe et al. 2011; Perissin and Wang 2012; Navarro-Sanchez and Lopez-Sanchez 2013; Del Soldato et al. 2018; Saleh and Becker 2019; Ziwen et al. 2019, Poreh and Pirasteh 2020). Many radar images and techniques were considered for the estimation of historical changes on the Earth's surface. For example, similar methods, such as the Small Baseline Subset (SBAS), have emerged with the effectiveness of the PSI approach (Murillo and Manuel 1995; Rudolph et al. 2006; Gourmelen et al. 2007; Dai et al. 2016).

In general, land subsidence in Mexico City occurs when large amounts of groundwater withdrawn from certain types of rocks, like fine-grained sediments. The water is partly responsible for holding the ground up, and then the rock compacts. We can say that when the 
water is withdrawn, the rocks can fall in on itself. The subsidence in Mexico City, which is due to groundwater extraction, began in the 1840s. Later, this phenomenon became extensive in the 1930s and 1950s (Carrillo 1947; Ortega-Guerrero et al. 1999; López-Quiroz et al. 2009; Rodell et al. 2009; Lopez-Quiroz et al. 2009; Ayazi et al. 2010; Ortiz-Zamora and Ortega-Guerrero 2010; Osmanoglu et al. 2011; Yan et al. 2012; Chaussard et al. 2014; Castellazzi et al., 2016a, b; Albano et al., 2016a, b; Castellazzi et al., 2016a, b; Suárez et al. 2018; Cigna et al., 2019a, b). The subsidence mechanism in Mexico City lacks enough natural water recharge (i.e. no extracted water replacement); consequently, further compaction of the clay layers is expected (Carrillo 1947; Cuevas 2004; Osmanoglu et al. 2011; Albano et al., 2016a, b). The subsidence is associated with natural compaction (i.e., overlying geological layers) and water pumping of the study area (Castellazzi et al., 2016a, b; Suárez et al. 2018; Cigna et al., 2019a, b).

Beyond the natural compaction, the main mechanism of the deformation in Mexico City is heavy water pumping. This operation results in the loss of aquifer storage and damage to engineered structures. Since the late 1950s, this subsidence has accelerated to a remarkable extent, and considerable correlated structural damage has been reported in the Mexico City area (Cabral-Cano et al. 2008; Osmanoglu et al. 2011; Yan et al. 2012). More than 20 million inhabitants in the metropolitan area face this extraordinary land subsidence hazard (http://www.en.unesco.org/creative-cities/mexico-city).

For example, in Mexico City Metropolitan Cathedral (which took 250 years to build), one side is settled nearly $2.44 \mathrm{~m}$ deeper than the other side. Furthermore, the cathedral is leaning to the left side (http://www.whc. unesco.org/en/list412).

Cabral-Cano et al. (2008) studied Mexico City's subsidence based on the InSAR methodology. By using ERS and ENVISAT-ASAR satellite data in the temporal baseline of 1996-2003, the authors pointed out that the subsidence rate in Mexico City has reached $370 \mathrm{~mm} / \mathrm{yr}$ (Fig. 1). It is controlled by the compaction of the quaternary lacustrine clays and silts. Castellazzi et al. (2016a, b) studied the land subsidence in major cities in the whole country, including Mexico City. Suárez et al. (2018) also estimated the ground subsidence in the city of Morelia, Mexico, by applying InSAR. Cigna et al. (2019a, b)

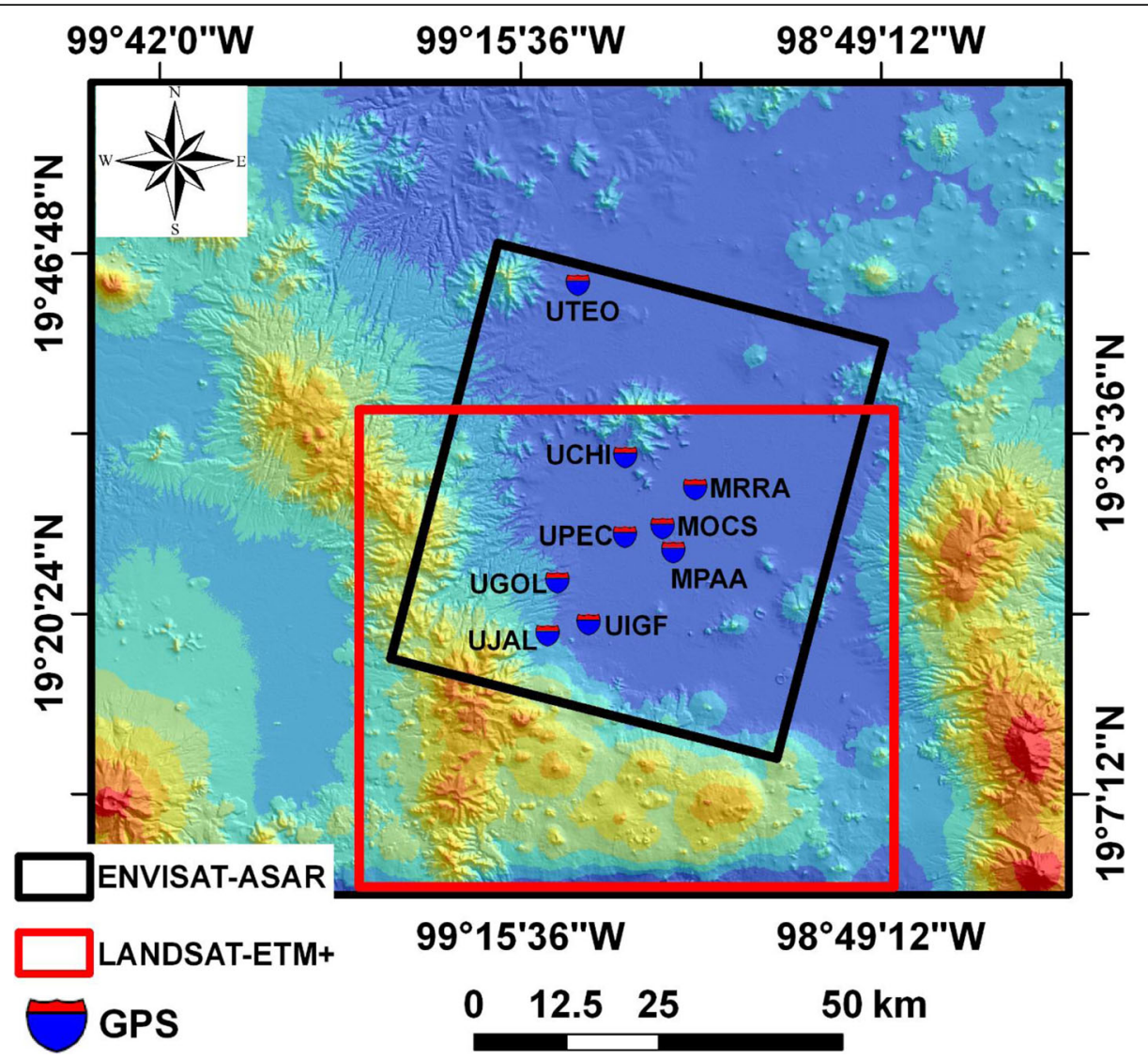

Fig. 1 The black rectangle shows the ENVISAT-ASAR data coverage area in the descending mode. The red rectangle shows the area with the detailed geological map of the study area (see Fig. 3), and Landsat ETM+ imagery from 25/11/2005. The nine installed GPS station locations, also depicted 
surveyed the wide area of surface deformation in urban areas and geothermal fields in the eastern Trans-Mexican Volcanic Belt, Mexico, by utilizing InSAR techniques.

Castellazzi et al. (2016a, b) used GRACE and InSAR data sets to assess groundwater storage loss remotely in the Mexico City area. Using the SBAS-InSAR algorithm to reveal areas subject to ground motion related to groundwater overexploitation, they noted that GRACE satellite data sets do not entirely detect the significant groundwater losses. As a solution, these data sets should be combined with other high-resolution satellite imageries. Chaussard et al. (2014) used ALOS data to retrieve the deformation rate in Mexico City for 2007-2011. Land subsidence in 21 areas and 17 cities are observed, and they found a maximum deformation rate of $300 \mathrm{~mm} / \mathrm{yr}$. Ortiz-Zamora and OrtegaGuerrero (2010) used a ground magnetic survey combined with lithologic logs to map the extension of basalts, ground surface data, and hydraulic data. The authors ran predictive simulations and field data to predict the Mexico City area's deformation rates from 1984 to 1989. Ortega-Guerrero et al. (1993) used hydraulic data from a network of monitoring wells, geotechnical data from core samples, and historical information for 1984-1989. The authors ran a mathematical model to predict future subsidence under the current pumping rates.

Strozzi and Wegmüller (1999) used ERS satellite data sets in the temporal baseline of 1995-1997 to monitor subsidence in Mexico City. They found $400 \mathrm{~mm} / \mathrm{yr}$ subsidence in the eastern part of Mexico City's community. They concluded that almost nine meters of subsidence have occurred in the Mexico City area over the last century because of water extractions. Yan et al. (2012) compared PSI (with Gamma-IPTA chain methodology) and SBAS for Mexico City's subsidence from 2002 to 2007 and explained each method's strengths and weaknesses. Lopez-Quiroz et al. (2009) analyzed 38 ENVI SAT images acquired between 2002 and 2007 and discovered $400 \mathrm{~mm} / \mathrm{yr}$ subsidence with InSAR. They also showed that the deformation is almost linear over time baselines. A PSI study based on ENVISATASAR data was carried out in the eastern part of Mexico City during a short temporal baseline (i.e., 2004-2006) by Osmanoglu et al. (2011), Castellazzi et al. (2016a, b), and Cigna et al. (2019a, b). They used only 23 images for PSI data analysis, which is the minimum number of sufficient imageries for PSI analysis. Finally, Sowter et al. (2016) used Sentinel for temporal baselines of 2014-2015. The SBAS (ISBAS) technique was utilized to measure the deformation rate of $240 \mathrm{~mm} / \mathrm{yr}$ along the LOS direction, equivalent to over $400 \mathrm{~mm} / \mathrm{yr}$ vertical rates (Zebker et al. 1997; Cigna et al., 2019a, b).
Despite the controlling procedure and the abovementioned research, we used ten years of InSAR data in this study to focus on the maximum $352 \mathrm{~mm} / \mathrm{yr}$ displacement rate (in LOS direction) occurring in the central and eastern parts of Mexico City. Our study covers a longer temporal baseline (between November 2002 and June 2010) and a wider area $\left(62 \times 56 \mathrm{~km}^{2}\right)$ than the previous studies. In this study, we analysed 52 ENVISATASAR data from November 2002 until June 2010 with a larger coverage area than that of Osmanoglu's work (Osmanoglu et al. 2011). We managed to extend the temporal baseline. As pointed out by Zebker et al. (1997), for $\mathrm{N}$ independent interferograms $(\mathrm{N}+1$ InSAR imageries), the temporally uncorrelated noise reduces by a factor of $1 / \sqrt{N}$. Therefore, this statement supports the current study while enhancing similar works' reliability performance (Cabral-Cano et al. 2008; Osmanoglu et al. 2011; Albano et al., 2016a, b).

In summary, the objectives and advantages of this study as compared to the existing research are (1) analyzing more InSAR imageries (longer temporal baselines), (2) working with a larger coverage area, (3) using accurate ENVISAT images in conjunction with more CGPS stations, and (4) conducting a detailed geohazard risk assessment of Mexico City-based on SVM integration.

\section{Study area}

When Spanish invaders conquered North America in 1521, they built Mexico City over the ruins of the Aztec civilization capital of Tenochtitlan. The old Aztec city was an island in Lake Texcoco (Figs. 2 and 3). The Spanish drained the lake over an extended time and expanded Mexico City onto the new land, where it exists today. Mexico City is built on highly compressible clays (Cuevas 2004). Almost the entire city stands on layers of sand and clay with thicknesses up to $300 \mathrm{~m}$ at some locations.

These soft, water-laden and loose sediments make the city uniquely vulnerable to subsidence, earthquakes, and other kinds of geohazards. The $100-\mathrm{km}$ long and $80-\mathrm{km}$ wide NE-SW-oriented Mexico Basin is located in the eastern sector of the Mexican Volcanic Belt (Fig. 3). This volcanic zone is the result of the subduction of the Cocos and Rivera oceanic plates underneath the North American plate. Morphologically, the Mexico Basin includes (a) volcanic ranges, composed of either polygenetic or monogenetic volcanoes, and (b) a series of fanlike knolls located at the base of each volcanic range. The intercalation of pyroclastic and epiclastic deposits and (c) flat-land areas results from the accumulation of lacustrine sediments of variable thicknesses interbedded with tephra layers (Ferrari et al. 1999; Arce et al. 2013). 


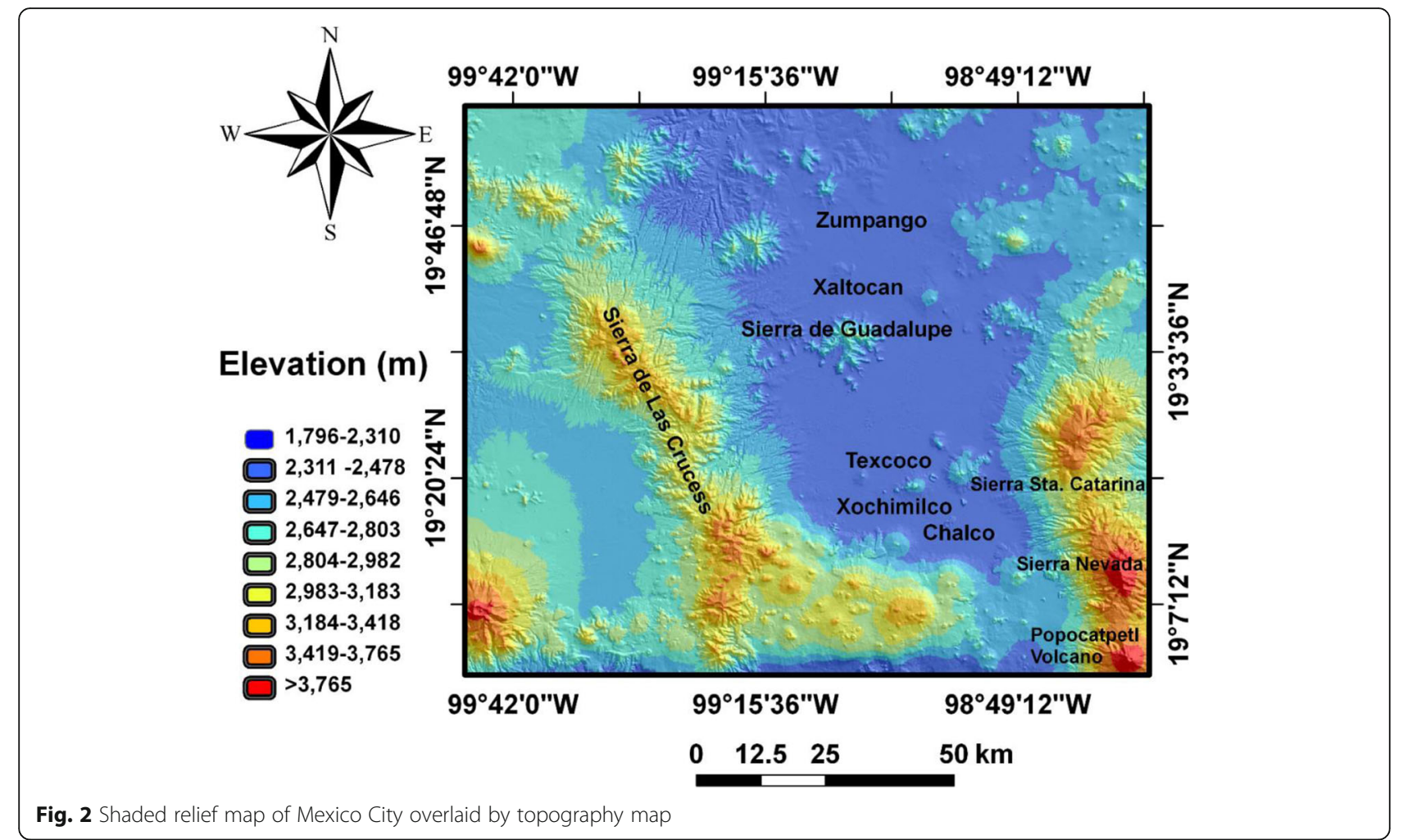

The lacustrine sediments of Mexico City exhibit very unusual behaviour; in some cases, the water content can surpass $500 \%$, the plasticity index sometimes exceeds I > $300 \%$, and the compression index could be in the order of 10 (Castellazzi et al., 2016a, b). The friction index of Mexico City clayey soils is comparable in magnitude to that of sands. Furthermore, the sediments do not show strength loss, not even when the cyclic loading amplitude is as high as $80 \%$. The sediments of Mexico City are a complex mixture of crystalline minerals and amorphous material with heterogeneous volcanic and lacustrine sediments (silty clay or clayey silt) (OrtegaGuerrero et al. 1993, Du et al. 2019).

\section{Data and methodology}

\section{Data gathering}

Figure 1 shows the study area in Mexico City with CGPS station locations, InSAR, and LANDSAT-ETM+ data coverage area. We used complementary data sets from nine GPS stations (daily data), thousands of Permanent Scatterers (PS) observations from ENVISAT-ASAR satellite, and optical remotely-sensed imageries. The deformation signature of the Mexico City area with temporal baselines of 1998-2012 and 2002-2010 from GPS and InSAR data, respectively, provides updated estimates, including related risk assessments. For some GPS stations, we do not have data from 1998, and some of the data have gaps and are of poor quality (see Fig. 4).
These nine GPS stations were installed and maintained by the University of Mexico. We used CGPS as the ground truth and calibration tool for the InSAR data. With more than six years (and eight years for one station) of CGPS and InSAR overlap, the two independent geodetical methodologies provide an updated picture of subsidence in Mexico City and its surrounding area in the first decade of the twenty-first century.

This study used the Landsat ETM+ image to classify the types of man-made structures and buildings' densities in the study area. Landsat ETM+ image with seven bands, acquired on $15 / 11 / 2005$, was processed by the U.S. Geological Survey (USGS). We used DORIS for SVM analysis incorporation with InSAR/PSI processing techniques. We also applied supervised classification using ENVI 4.8 under Windows and Linux platforms for image processing.

\section{GPS}

All of the CGPS stations are inside the ENVISAT-ASAR data coverage (black frame in Fig. 1). UCHI, UGOL, UIGF, and UGAL are located either on the andesitebasalt lava or on the tephra deposits around Mexico City (Osmanoglu et al. 2011). CGPS data was provided by the University of Mexico and has been analyzed by utilizing the precise point positioning of the ITRF-2000 reference frame (Dixon et al. 2000; Altamimi et al. 2002; Hilley et al. 2004; Argus 2007). The GPS data have been 


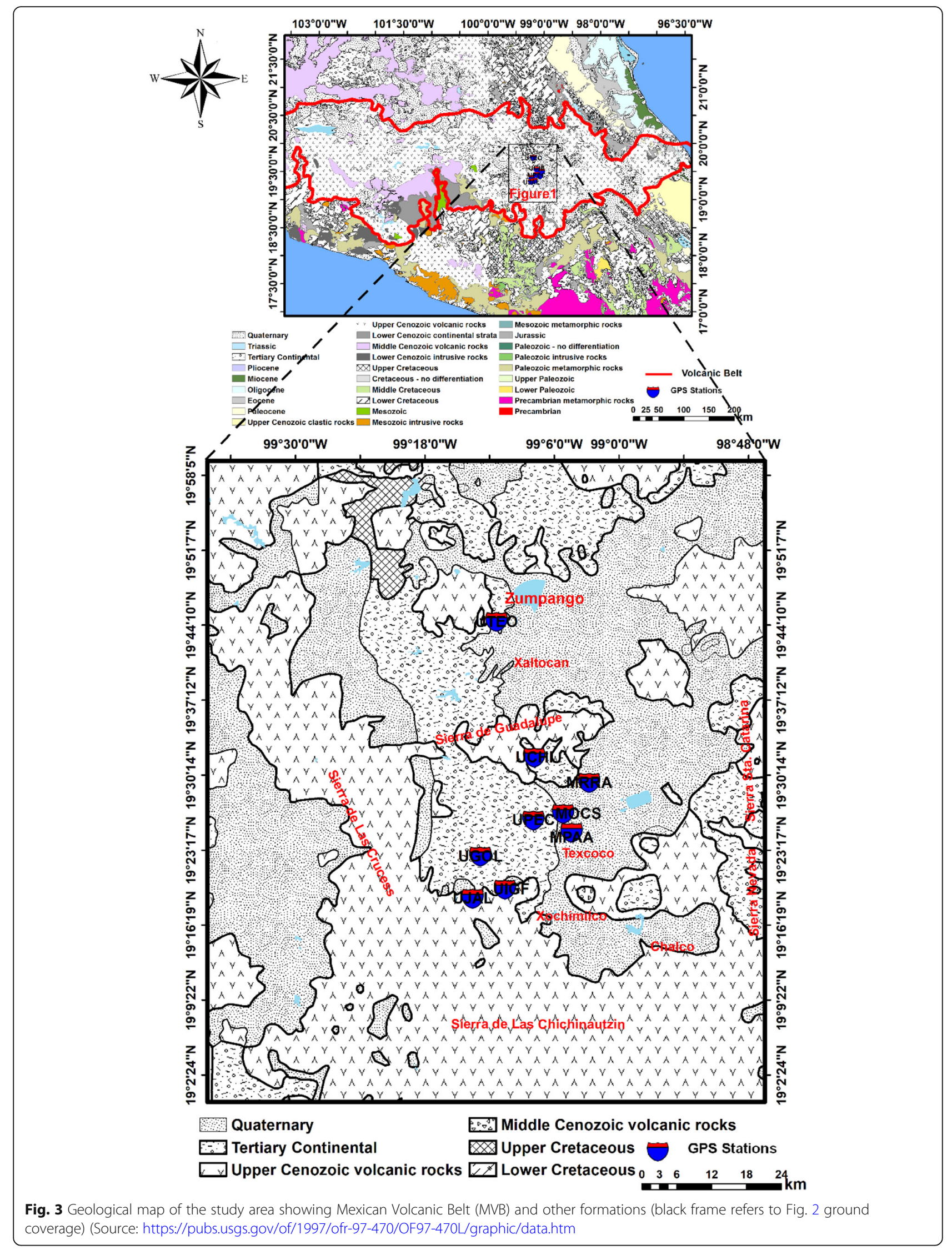



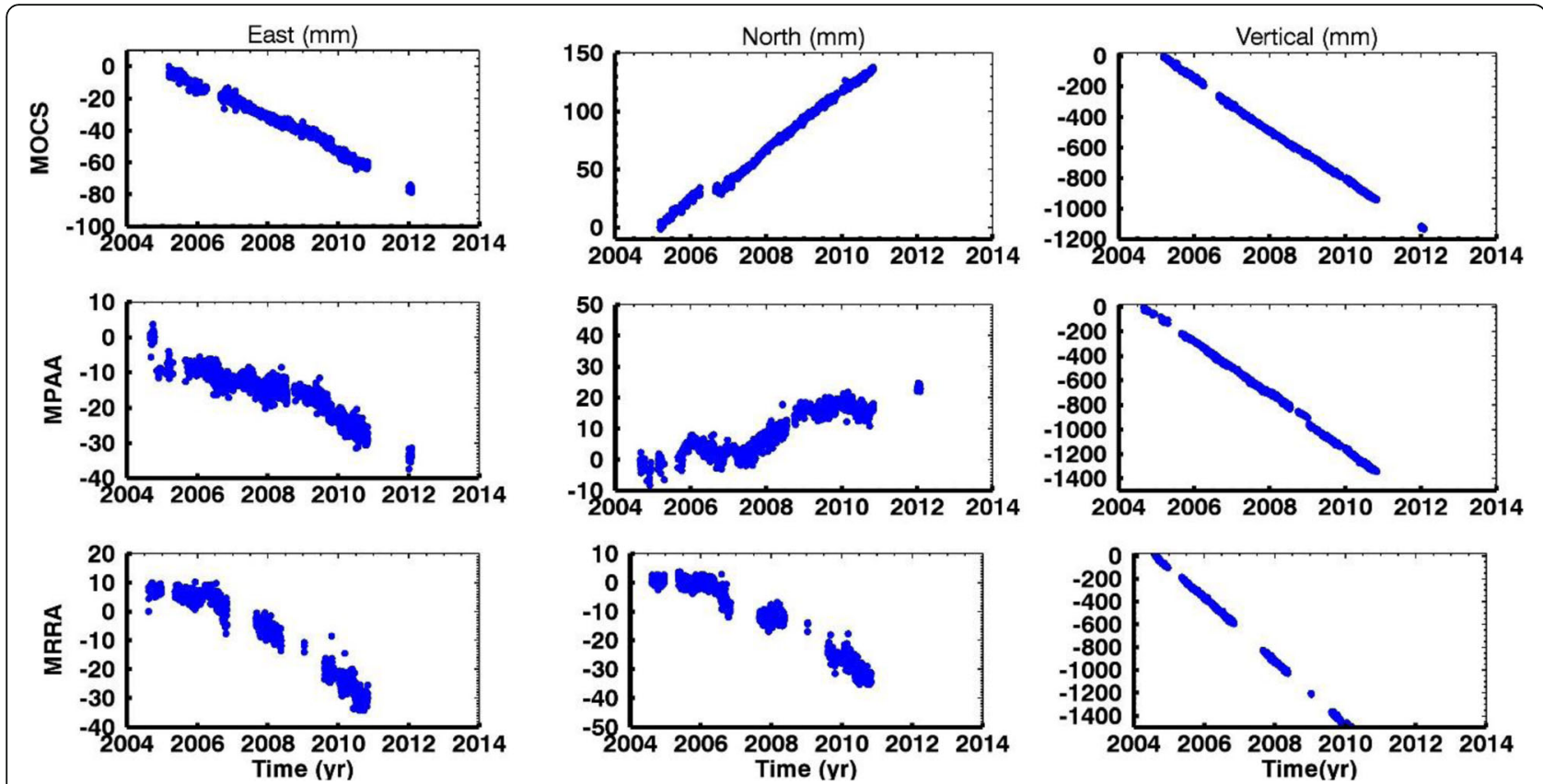

Fig. 4 North, east, and vertical components of motion observed by the permanent GPS stations (blue points) using point positioning and the ITRF-2000 reference frame. GPS rates are provided in Table 1

converted from the ITRF coordinate system to the north, east, and vertical coordinates were utilizing the national coordinate system. The comparison of PS with the GPS data is attempted, and the velocities are compared to a reference point. In the Mexico City area, the tectonics (i.e., plate movements) also plays a very important role, which has an undeniable effect on the InSAR reflectors, including PS's reference point. In other words, the selection of reliable coordinate systems is crucial for the fusion of InSAR and GPS.

This study calculated velocity and uncertainty for each CGPS station by linear regression analysis. For details of the procedures and estimation of uncertainties for GPS measurements, refer to Dixon et al. (2000) and Sella et al. (2002). The results of the CGPS data analysis are provided in Fig. 4 and Table 1. These data are presented in "absolute" coordinates (latitude, longitude, and height). All of the vertical (UP) components show negative values (subsidence) with a maximum of $-275.3 \pm$ $3.5 \mathrm{~mm} / \mathrm{yr}$. It identifies subsidence in the MRRA station or the easternmost CGPS station (Fig. 1). A minimum of $-0.3 \pm 2.5 \mathrm{~mm} / \mathrm{yr}$ is observed in the UCHI station, which is located on the andesite-basalt lava or tephra deposits (see Fig. 3). GPS data could be contaminated with several potential noises. Because the study area is small, orbital effects are assumed to be spatially uniform. Despite different temporal coverages of CGPS and InSAR data, we have managed to compare these two independent geodetic methods. For comparison of GPS and PSI data, GPS-observed data should be aligned with to the PSI points. The velocities $\mathbf{V}_{\mathbf{L O S}}$ measured by the PS

Table 1 Deformation rates of CGPS stations in the Mexico City area (point positioning solution, ITRF-2000 networks). For the location of CGPS stations, see Fig. 2. For geology, see Fig. 3

\begin{tabular}{|c|c|c|c|c|}
\hline Station & $\mathrm{N}$ [mm/year] & $\mathrm{E}$ [mm/year] & V [mm/year] & Rock/soil formation \\
\hline MOCS & $24.1 \mp 0.7$ & $-10.3 \mp 0.6$ & $-164.7 \mp 2.8$ & Lacustrine \\
\hline MPAA & $3.6 \mp 0.7$ & $-3.6 \mp 0.7$ & $-220.3 \mp 2.9$ & Lacustrine \\
\hline MRRA & $-0.6 \mp 0.8$ & $-6.7 \mp 0.7$ & $-275.3 \mp 3.5$ & Lacustrine \\
\hline $\mathrm{UCHI}$ & $0.7 \mp 0.6$ & $-7.23 \mp 0.6$ & $-0.3 \mp 2.5$ & Alluvial (Basalt?) \\
\hline UGOL & $0.5 \mp 0.6$ & $-8.0 \mp 0.7$ & $-0.7 \mp 2.8$ & Alluvial (Basalt?) \\
\hline UIGF & $-1.5 \mp 0.6$ & $-8.0 \mp 0.7$ & $-0.7 \mp 2.8$ & Basalt \\
\hline UJAL & $-1.9 \mp 0.6$ & $-7.8 \mp 0.7$ & $-3.0 \mp 2.8$ & Basalt \\
\hline UPEC & $1.0 \mp 1.0$ & $-7.4 \mp 1.0$ & $-82.3 \mp 5.0$ & Alluvial (Basalt?) \\
\hline UTEO & $-2.6 \mp 0.07$ & $-6.9 \mp 0.8$ & $-2.1 \mp 3.3$ & Lacustrine \\
\hline
\end{tabular}


technique are in the Line-Of-Sight (LOS) direction, and the GPS measurements are projected to this direction via:

$$
\mathrm{V}_{\mathrm{LOS}}=\mathrm{V}_{\text {East }} \psi_{\text {East }}+\mathrm{V}_{\text {north }} \psi_{\text {north }}+\mathrm{V}_{\text {Vertical }} \psi_{\text {Vertical }}
$$

Where each $\psi$ component is known as a directional cosine $\psi=\left[\psi_{\text {East }}, \psi_{\text {north }}, \psi_{\text {Vertical }}\right]$. For example, LOS's vertical component has a directional cosine of $\cos \left(\theta^{\circ}\right)$. Therefore, with only vertical movement, the LOS velocity should be divided by $\cos \left(\theta^{\circ}\right)$ to represent the exact amount of the vertical component of motion. It should be considered in the LOS interpretations. Regarding this setting, we can infer LOS data as a vertical displacement with an error rate of almost $8 \%\left(\cos \left(23^{\circ}\right)=0.92\right)$ for ENVISAT-ASAR satellites. Despite a relatively small amount of horizontal deformation rates in the Mexico City area (based on CGPS data) in comparison with a vertical deformation rate, we consider PSI velocities as a combination of vertical and horizontal velocities (based on Eq. 1).

Table 1 Deformation rates of CGPS stations in the Mexico City area (point positioning solution, ITRF-2000 networks). For the location of CGPS stations, see Fig. 1. For geology, see Fig. 3.

\section{Interferometric SAR and PSI}

In this study, we used 52 ENVISAT-ASAR scenes to analyze the subsidence in the study area. The study area covers a temporal baseline between November 2002 and June 2010. The 05/05/2006 acquisition has been selected as the master scene to minimize the effects of spatial and temporal baselines (Zebker et al. 1997; Scharroo and Visser 1998; Hanssen and Bamler 1999). The ENVISATASAR imageries of $62 \mathrm{~km} \times 56 \mathrm{~km}$ area are centered cover Mexico City's historic downtown. In the first step, we ran the crop by applying Delft Object-oriented Radar Interferometry Software (DORIS) method. Next, we oversampled the data by using a factor of two in range and azimuth to avoid any undersampling of the interferograms, especially during the resampling of the slave acquisition (Bell et al. 2002). By running this step, we prevented aliasing over the data. In the interferometry step, scenes were oversampled by a factor of two in range and azimuth to make each pixel (originally $4 \mathrm{~m} \times$ $20 \mathrm{~m}$ ) approximately $2 \mathrm{~m} \times 10 \mathrm{~m}$. DORIS was used to make differential interferograms of imageries (Hanssen and Bamler 1999). To reduce the orbital effect in the produced interferograms, we used precise orbit data (DOR and VOR) from the TU-Delft University that were supposed to significantly minimize orbital errors significantly (Scharroo and Visser 1998). We appended useful orbit data to the images. We did not run the Porbits step (in DORIS software) in our data.

Table 2 illustrates the baseline information (perpendicular, temporal, and Doppler baselines) for 52 ENVI SAT-ASAR satellite imageries. We acquired images in the descending mode for the study area. Imageries are given in the format of YYYYMMDD (first and fifth columns). Major factors influencing the InSAR Phase measurements are (Hanssen 2001):

$$
\varnothing=\phi_{\text {atm }}+\phi_{\text {orb }}+\phi_{\text {def }}+\phi_{\text {scat }}+\phi_{\text {DEM }}+\phi_{\mathrm{n}}
$$

$\phi$ def is the part connected to deformation, $\phi D E M$ is the topographic phase contribution, and porb is the orbital part error that could be minimized by using precise orbital data. Фatm is the atmospheric phase screen, and pscat is the change in the scattering attributes of the scatterers during the time that may not fall in the urban area. Finally, $\phi n$ is the noise part of the phase, which is for strong scatterers and would be negligible. Data analysis and probable errors are explained in Hanssen and Bamler (1999), Hanssen (2001) and Kampes (2005).

The geo-referencing accuracy of standard ENVISATASAR images concerning reference ellipsoid is approximately $12 \mathrm{~m}$ in azimuth and $60 \mathrm{~m}$ in range direction. To obtain as high as possible level of accuracy in geolocation, SRTM 3 arcsec data have been used to the scale of 10 and $15 \mathrm{~m}$ in azimuth and range direction, respectively. Figure 5 shows the ENVISAT-ASAR data configuration used in this study. This figure depicts the temporal and perpendicular baselines of the ENVISAT-ASAR data for the study area in Mexico City. Scene 20,060,505 has been selected as a master image to reduce the orbital error and maximize the coherence. In Fig. 6, interferograms are presented. Interferograms are not georeferenced (in radar coordinates). Each color cycle (or fringe) shows a movement at the rate of $2.83 \mathrm{~cm}$ in LOS direction.

We applied the TU-Delft approach for analyzing the data and determining the average subsidence rates, including the deformation time series for each pixel on the ground (Ferretti et al. 1999; Wang et al. 2010; Albano et al., 2016a, b; Poreh et al. 2017; Du et al. 2019; Cigna et al., 2019a, b). CGPS stations in the area cover SAR's data and the nearby region. It was employed to compare InSAR data results with the CGPS data for calibrations and ground truth controls. This study used the phase unwrapping method to solve the phase history of a single-pixel called periodogram (Osmanoglu et al. 2011). As pointed out in previous studies (Cabral-Cano et al. 2008; Osmanoglu et al. 2011), the subsidence in Mexico City is almost linear in time. Therefore, the most accurate model appears to be the linear model. Note that in 
Table 2 Baseline information of ENVISAT-ASAR imageries

\begin{tabular}{|c|c|c|c|c|c|c|c|}
\hline Date & B.Temp [days] & B.Perp [m] & B.Dopp [Hz] & Date & B.Temp [days] & B.Perp [m] & B.Dopp [Hz] \\
\hline $20,021,122$ & -1260 & 454.6 & 32.34 & $20,051,007$ & -210 & -511.2 & 2.88 \\
\hline 20,030,307 & -1155 & -643.1 & -65 & $20,051,111$ & -175 & 283.5 & 10.23 \\
\hline $20,030,411$ & -1120 & 93.3 & -103.42 & $20,051,216$ & -140 & -387.3 & 12.47 \\
\hline $20,030,620$ & -1050 & -145.9 & -71.75 & $20,060,120$ & -105 & -1271.8 & 12.74 \\
\hline $20,030,725$ & -1015 & -366.9 & -20.76 & $20,060,224$ & -70 & -677.2 & 8.71 \\
\hline $20,030,829$ & -980 & -39.8 & 30.1 & $20,060,331$ & -35 & -1120.2 & 0 \\
\hline $20,031,003$ & -945 & -480.8 & 66.21 & $20,060,505$ & 0 & 0 & 0 \\
\hline $20,031,107$ & -910 & -1053.4 & 54.39 & $20,060,609$ & 35 & -567.3 & 5.04 \\
\hline $20,031,212$ & -875 & -992.3 & -91.13 & $20,060,714$ & 70 & 815.5 & 0.01 \\
\hline $20,040,116$ & -840 & -480.2 & 33.55 & $20,061,201$ & 210 & -398.8 & 8.76 \\
\hline $20,040,220$ & -805 & -962.2 & 26.74 & $20,070,105$ & 245 & 63.9 & 15.46 \\
\hline $20,040,326$ & -770 & 785.5 & 29.33 & $20,070,209$ & 280 & -336.6 & 9.66 \\
\hline $20,040,430$ & -735 & -670.9 & 31.81 & $20,070,316$ & 315 & -52.9 & -0.54 \\
\hline $20,040,604$ & -700 & 368.5 & 25.39 & $20,070,907$ & 490 & -190.8 & 0.01 \\
\hline $20,040,813$ & -630 & -841 & 22.06 & $20,071,012$ & 525 & -456.9 & 4.21 \\
\hline $20,040,917$ & -595 & 171.3 & 22.34 & $20,080,509$ & 735 & -268.5 & 11.04 \\
\hline $20,041,022$ & -560 & 607.8 & 27.08 & $20,080,926$ & 875 & -400 & 10.72 \\
\hline $20,041,126$ & -525 & -194.5 & 32.09 & $20,081,031$ & 910 & -302.9 & 9.41 \\
\hline $20,041,231$ & -490 & -253.8 & 32.69 & $20,081,205$ & 945 & -305.6 & 10.57 \\
\hline $20,050,204$ & -455 & -520.6 & 36.04 & $20,090,320$ & 1050 & 59.4 & 3.34 \\
\hline $20,050,311$ & -420 & -112.6 & 28.18 & $20,091,016$ & 1260 & -528.4 & 1.14 \\
\hline $20,050,415$ & -385 & 143.7 & 24.16 & $20,091,225$ & 1330 & -346.7 & 7.37 \\
\hline $20,050,520$ & -350 & -285.4 & 35.07 & $20,100,305$ & 1400 & -382.9 & 3.56 \\
\hline $20,050,624$ & -315 & 297.7 & 29.24 & $20,100,409$ & 1435 & -184 & 15.86 \\
\hline $20,050,729$ & -280 & -96.9 & 25.77 & $20,100,514$ & 1470 & -64.3 & 9.62 \\
\hline $20,050,902$ & -245 & 266.7 & 32.08 & $20,100,618$ & 1505 & -225.8 & 10.46 \\
\hline
\end{tabular}

Note: B. Temp is the temporal baseline (time difference) between master and slave acquisitions, B. Perp is the perpendicular baseline between orbits of the master and slave scenes, and B. Dopp is the difference between the Doppler centroid frequencies of master and slave scenes

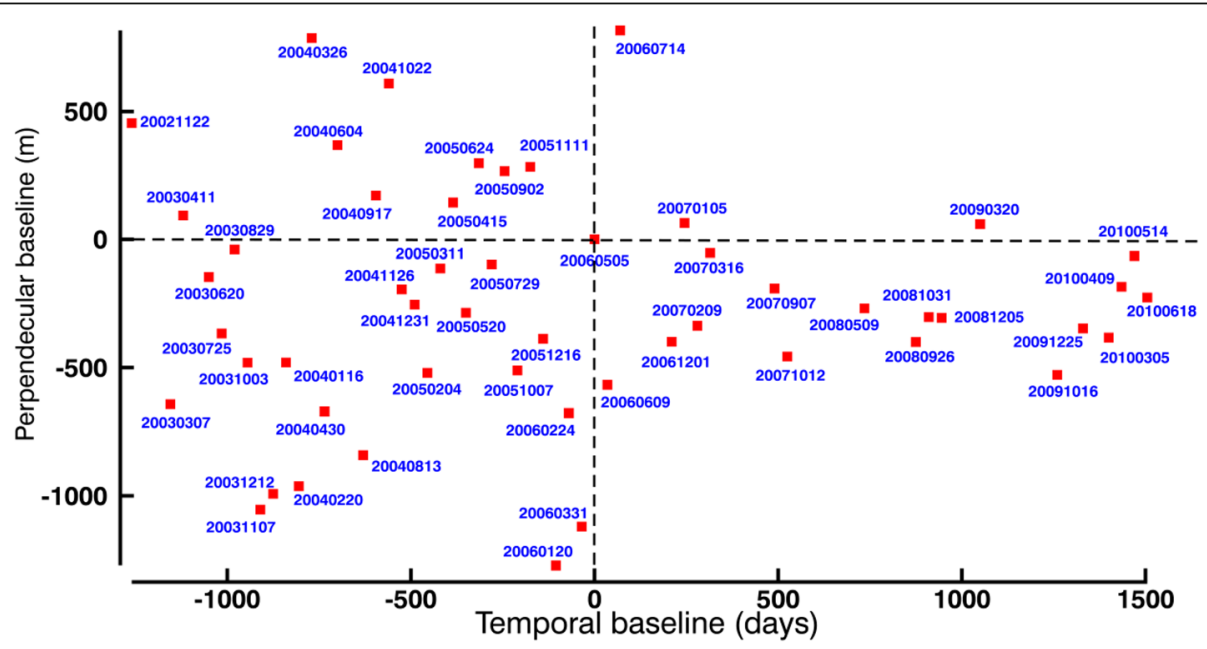

Fig. 5 ENVISAT-ASAR data sets configuration 


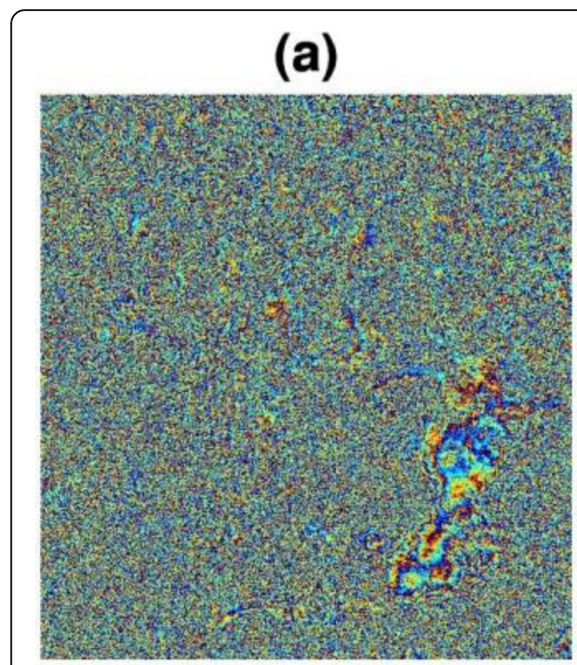

(d)

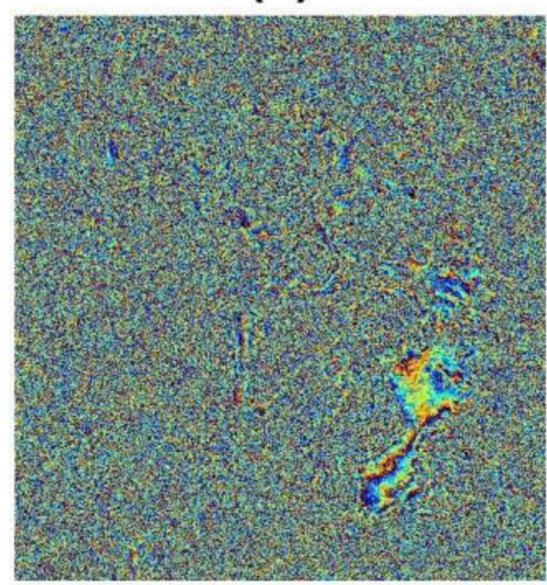

(g)

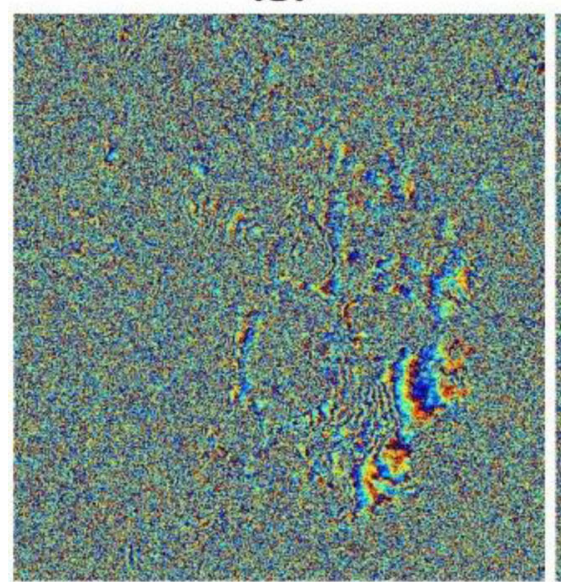

(b)

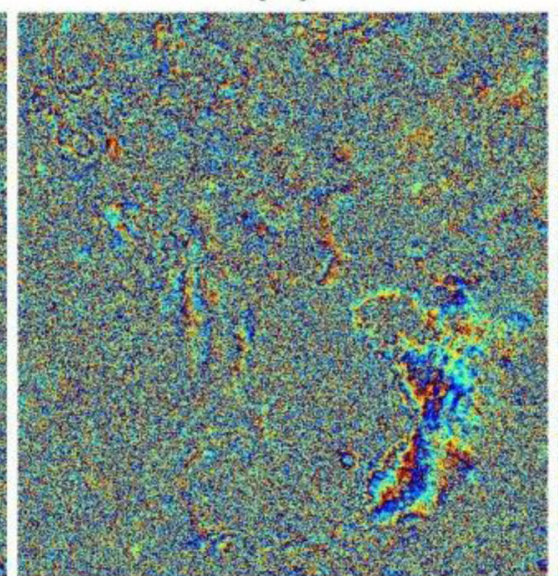

(e)

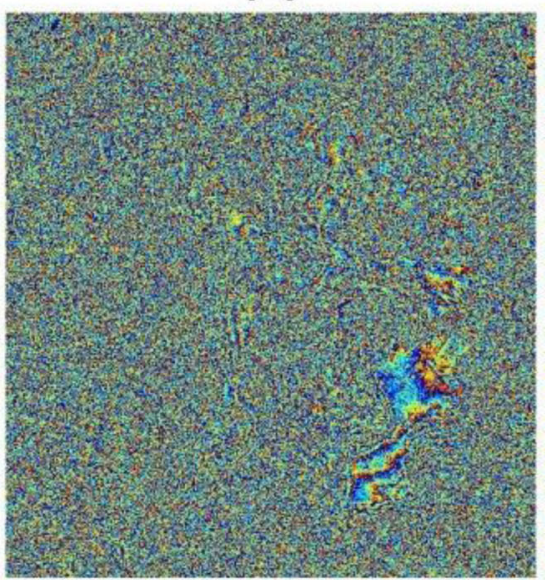

(h)

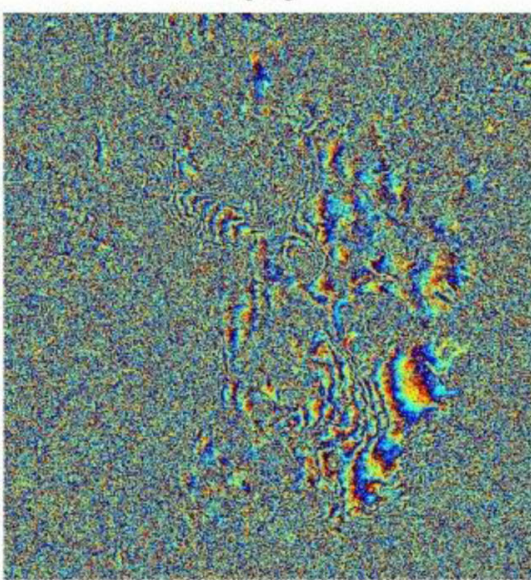

(c)

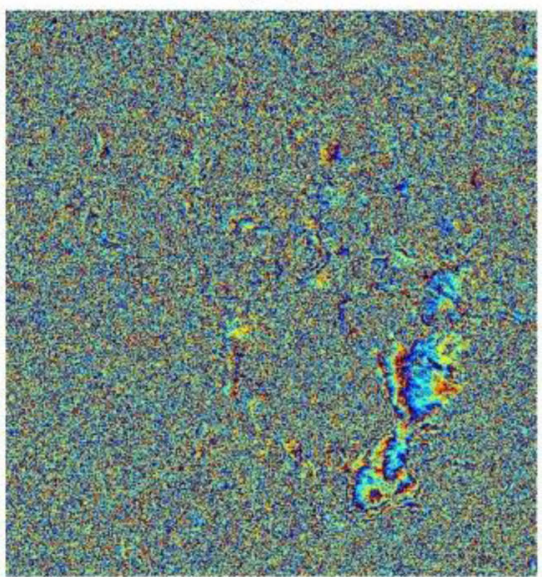

(f)

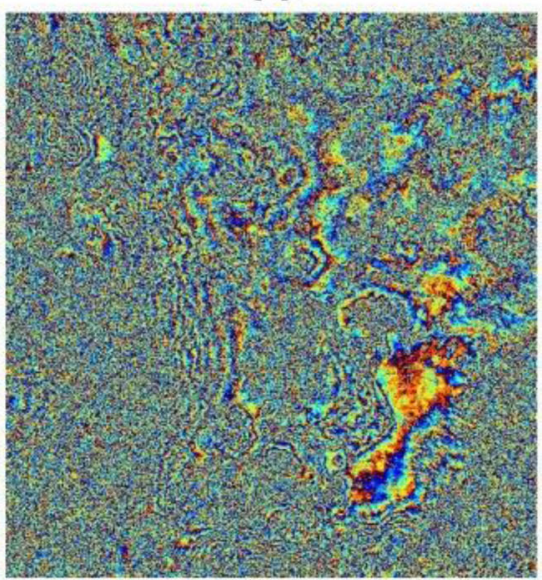

(i)

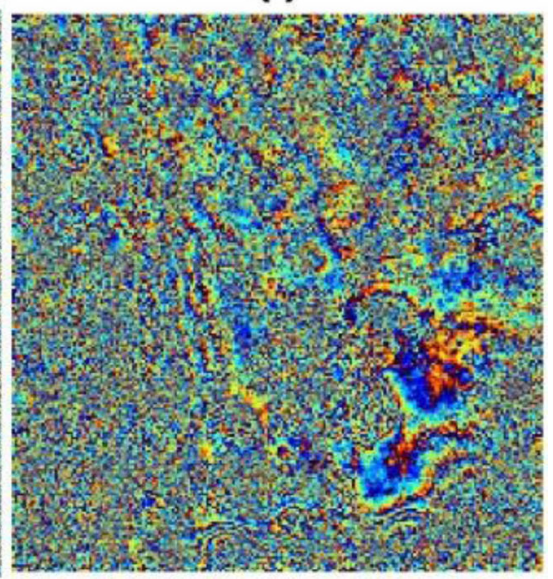

Fig. 6 Differential interferograms (from 51 interferograms) for Mexico City study area. Images (a)-(i) are the interferograms between the master image and radar images acquired on 2003/04/11, 2003/08/29, 2004/09/17, 2004/11/26, 2004/12/31, 2005/07/29, 2005/09/02, 2005/11/11, and 2007/03/16, respectively. (For characteristics of each image, see Table 2) 
PSI data analysis philosophy, non-linear displacements between neighboring scatterers are negligible. Nonetheless, we applied different deformation models and statistical hypothesis tests in unwrapping the steps to minimize the phase ambiguity errors. The PSI analysis's reference height is fixed to $2240 \mathrm{~m}$ to reduce the topographic phase errors efficiently. We used the PSC selections method and considered the threshold of dispersion index with the selection of 300-m fixed grid size.

\section{Building density classification}

In this study, we used the Landsat ETM+ image (with seven bands) dated 15/11/2005. We collected the satellite image from the University of Maryland (http://www.unesco.org). We classified the extension of populated buildings from the image. We used the False Color Composite (FCC) (2:3:5) to generate the RGB image. This study applied the SVM method on the RGB image to classify the populated buildings from the study area and to give a sense of the densities of the buildings (Fig. 7).

SVM is a well-known classification method that currently has wide applications in image processing and machine learning. This SVM statistical method is designed for recognizing different patterns, classification, and regression analysis. In the simplest form, SVM classification finds a hyper plan such as a $\forall i \llbracket y \rrbracket \_i$ (x_i.w + b)-1 problem that could segregate two classes by the minimization of the following Lagrange equation (Hilley et al. 2004):

$$
\frac{1}{2}\|\mathbf{w}\|^{2}-\sum_{i=1}^{L} \alpha_{i} \mathbf{y}_{\mathbf{i}}\left(\mathbf{x}_{\mathbf{i}} \cdot \mathbf{w}+\mathbf{b}\right)+\sum_{\mathbf{i}=\mathbf{1}}^{\mathrm{L}} \boldsymbol{\alpha}_{\mathbf{i}}
$$

Where $\forall \mathbf{i}, \mathbf{\alpha}_{\mathbf{i}} \geq \mathbf{0}$, and $\mathbf{L}$ are the number of training points, and $\mathbf{w}=\sum_{\mathbf{i}=\mathbf{1}}^{\mathrm{L}} \boldsymbol{\alpha}_{\mathbf{i}} \mathbf{y}_{\mathbf{i}} \mathbf{x}_{\mathbf{i}}$

In this study, we used three training sets to classify the patterns. We considered three different kinds of building density classes as the training sets. We selected three areas with three Regions Of Interest (ROI) to apply supervised SVM classification analysis. These three areas include (i) highly populated areas (dense building distribution), (ii) sparse building distribution with less density, and (iii) areas that are mountainous and unpopulated. After selecting these three ROI, we imposed the SVM method to classify these areas mentioned above with minimum error.

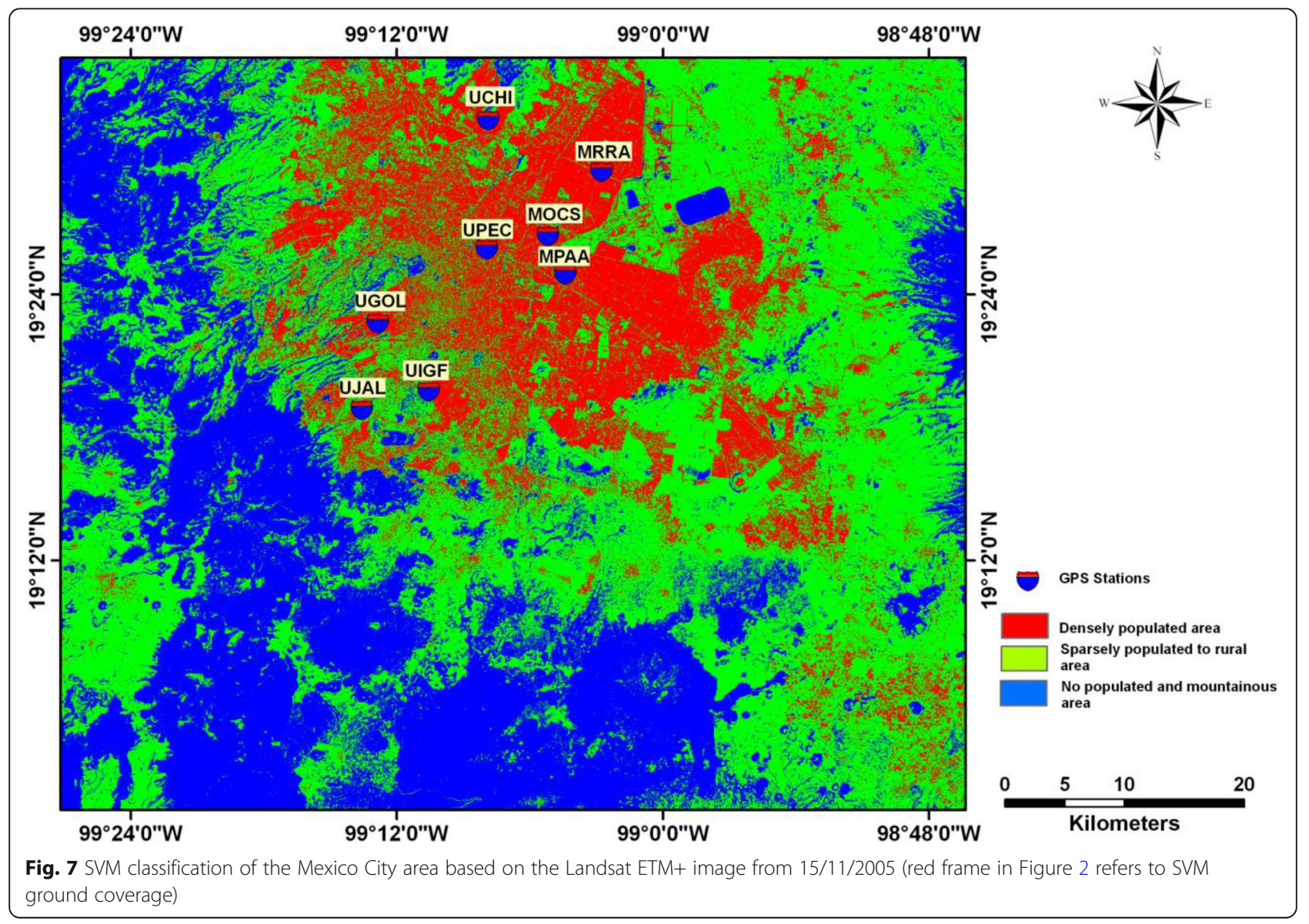




\section{Results and discussion}

The ability to make combined measurements from InSAR, GPS, and optical remote sensing imageries may be a powerful tool for studying Mexico City's subsidence and related risk management. The combination of CGPS and PSI methods seems straightforward. However, this process requires careful analysis since we do not have radar reflectors (PSs) in the exact location of each CGPS station. Therefore, the PSI approach is a relative method in comparison with the absolute GPS methodology, but in the absence of other more accurate methodologies such as GPS and levelling, it is the most trusted methodology.

\section{CGPS}

As pointed out by Osmanoglu et al. (2011) and CabralCano et al. (2008), the eastern and central parts of Mexico City (i.e. the most populated areas in the Mexico City community have undergone a high degree of subsidence. Table 1 depicts the CGPS results of the displacement in Mexico City, and Fig. 4 illustrates the extraordinary subsiding in the central and eastern parts of the Mexico City community. All CGPS stations show negative values (subsidence) in UP (vertical) components (Fig. 4). The natural compaction of basins is causing slow subsidence in rates of a few millimeters per year in areas like Mexico City; however, the pumping of the wells is the essential factor of the subsidence (OrtegaGuerrero et al. 1993). In comparison, subsidence based on groundwater extractions has rapid rates of ten centimetres per year (Nelson 2000; Cabral-Cano et al. 2008). For almost all of the CGPS stations in the study area, seasonal variations in Vertical components are negligible. The GPS data shows high agreement with the previous studies in this area (Cabral-Cano et al. 2008; Osmanoglu et al. 2011).

The permanent GPS station UIGF (see Fig. 4) was installed in 1998 in the Mexico City metropolitan area. MOCS, MPAA, and MRRA stations have been continuously recording the subsidence since 2005 with high temporal resolutions. These CGPS stations, which are located in the high subsidence region, record the vertical subsidence in the range of $-164.7 \pm 2.8$ and $-275.3 \pm$ $3.5 \mathrm{~mm} / \mathrm{yr}$. The highest vertical subsidence in the study area belongs to the station MRRA with a rate of $275.3 \pm 3.5 \mathrm{~mm} / \mathrm{yr}$. We recorded $-2.2 \pm 2.7 \mathrm{~mm} / \mathrm{yr}$ vertical subsidence for UIGF station. The station UPEC, located farther to the west (see Fig. 1), shows vertical subsidence in rates of $-82.3 \pm 0.7 \mathrm{~mm} / \mathrm{yr}$ with a negligible amount of seasonal variations. Some of the other CGPS stations show poor and unreliable data distributions. For instance, the stations UTEO, UJAL, and UCHI show lots of gaps and missing data.

\section{InSAR and PSI}

In the InSAR and PSI techniques, the displacements are resolved in the Line-Of-Sight (LOS) direction. This study is not in the three orthogonal displacement vectors; therefore, the combination with CGPS stations must be dealt with very carefully. Figure 8 depicts the PSI rates in the Line-Of-Sight (LOS) direction for Mexico City's subsidence during 2002-2010. Most of the available PSs time series does not address the issue of seasonal variability; thus, the amount of aquifer recharge is weaker. The PSI rate is increasing eastward and showing a massive amount of movement towards the center of the basin where the clay-rich sediment package is thickest.

Figure 8 shows subsidence through the eastern and central parts of the city (from November 2002 until June 2010). The maximum amount of $352 \mathrm{~mm} /$ year displacement in the LOS direction occurs in the eastern part of the city toward the remnant of Lake Texcoco (see Fig. 2). PSI rates are shown in Fig. 8, and nine GPS locations are overlaid on the shaded relief map of the STRM 3 arcsec data (http://www. glcf.umd.edu) (Fig. 8). For each pixel, a time series of displacements in the temporal baseline (November 2002-June 2010) has been plotted. These are used later to compare GPS with PSI data for calibration and validation.

Figure 9 shows the histogram of LOS deformation rates, which is strongly skewed to negative values. The J-shape distribution of the deformation rates is linked to the record of a strong subsidence pattern in Mexico City. The cause of deformation is probably due to groundwater extraction and compaction of the overlying geological layers. Other factors, such as tectonic movements of the plates mostly in the north direction, have a small effect on the existing PSI rates. The most common deformation rates are between -20 and $+2 \mathrm{~mm} / \mathrm{yr}$. The subsidence is more visible when the geological composition of the underground is associated with the fluvial clay sequences and, of course, not with the volcanic rock series. A comparison with previous InSAR and PSI works shows a high amount of agreement with the shape and subsidence rate (CabralCano et al. 2008; Osmanoglu et al. 2011).

Table 3 illustrates nine GPS stations' deformation rates inside the ENVISAT-ASAR data coverage area (see Fig. 1) and the closest PSI rates to those stations. It shows that the PSI and the CGPS rates are in agreement (see Fig. 10). Moreover, to summarize, more than 600,000 points have been selected as permanent scatterers in the study area. For these points, the authors calculated the time series (2002-2010) and radar scatterers' height. The PSs density in the study area is $240 \mathrm{PSs} / \mathrm{km}^{2}$.

\section{Comparison of PSI with CGPS stations and validation}

The PSI deformation rates measure the time interval between the generated interferograms, while the CGPS 


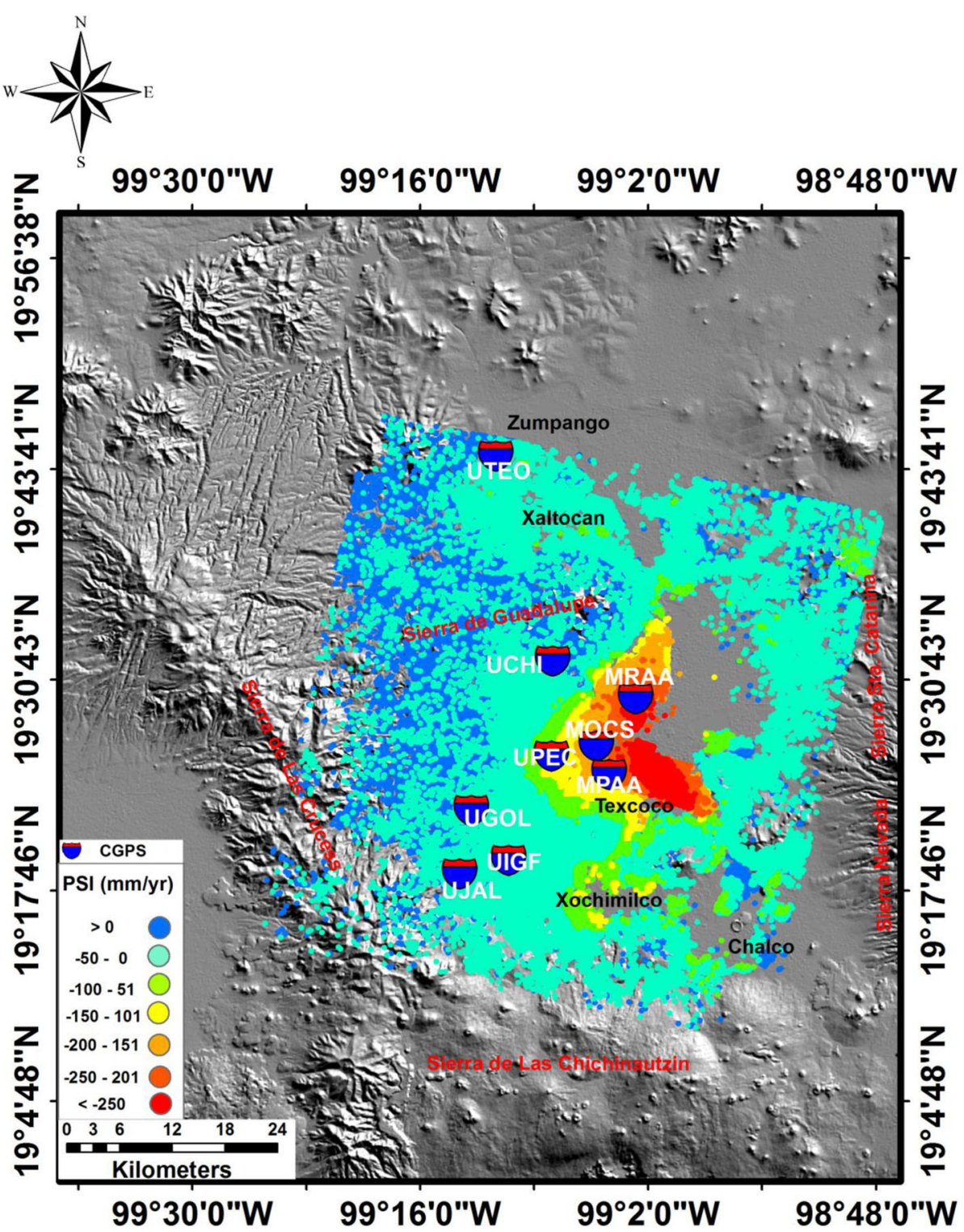

Fig. 8 PSI deformation rates of the Mexico City area for the temporal baseline of 2002-2010

stations measure in the constant rate of daily data. However, more than six (and eight for one station) years of overlaps can help us to compare CGPS stations with PSI data. Despite the poor quality and gaps for some CGPS stations (for instance, UTEO and UJAL), data from other CGPS stations could be compared with the PSI-derived deformation rates.

The accuracy of the PSI method can be measured in subcentimetres if a sufficient number of imageries are utilized in PS analysis (Ferretti et al., 2011a, b). We compared the outcomes of this research with nine independent CGPS stations to assess the accuracy of the PSI. We found that the is an improvement of the previous studies. Table 2 lists the LOS rates obtained from point positioning GPS and PSI analysis. For each GPS station, a search was conducted to find the closest PSI point's rates. PSI points close to the CGPS stations show similar rates of subsidence in the Mexico City metropolitan area. Figure 10 shows the graph interpretation of Table 2. A one-to-one line shows perfect agreement between GPS and PSI points, leading to acceptable PSI analysis in the Mexico City study area.

Because of the low incidence angle $\left(\sim 23^{\circ}\right)$ of the ENVI SAT-ASAR imageries, most of the PSI recorded displacements are from vertical movements of the terrain. This measurement justifies the perfect agreement between two independent displacement monitoring tools (PSI and CGPS). Furthermore, recorded deformation rates from independent CGPS stations of MOCS, 


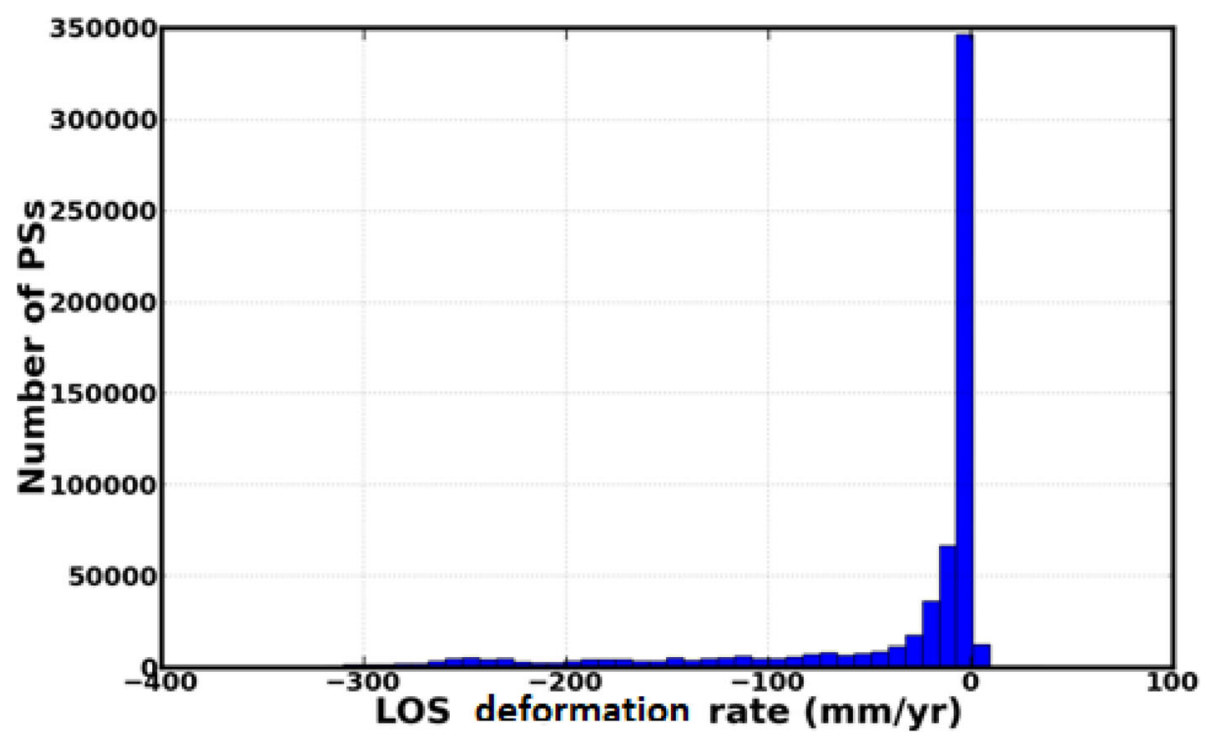

Fig. 9 Histogram of PSI's deformation rates for Mexico City study area

MPAA, MRRA, and UPEC confirm that the horizontal movements are small and do not follow a preferred direction. For instance, MPAA and UPEC are horizontally moving in the northwest direction. MOCS is moving horizontally almost to the north, and MRRA is moving in a southwest direction. On the other hand, a comparison with PSI histogram (Fig. 9) shows that extraordinarily high displacements (rates less than $-20 \mathrm{~mm} / \mathrm{yr}$ ) occur within the Mexico City metropolitan area. Since the two independent methods, PSI and CGPS, with different time intervals are in agreement; the seasonal behaviors are negligible.

\section{LOS GPS and average PSI comparison}

For each CGPS station, we selected a subset of PSs located nearby to the CGPS stations to test the stability of CGPS stations with their surroundings. The comparison of CGPS and PSI displacement results is illustrated in Fig. 11.

Table 3 Comparisons of LOS' rates of movements for GPS and PSI

\begin{tabular}{lll}
\hline Site & GPS-point Positioning [mm/year] & PSI [mm/year] \\
\hline MOCS & -157.37 & -162.48 \\
MPAA & -199.58 & -183.71 \\
MRRA & -253.34 & -254.12 \\
UGOL & -11.43 & -18.73 \\
UPEC & -83.3 & -98.94 \\
UIGF & -3.84 & -4.86 \\
UJAL & -1.70 & -2.99 \\
UCHI & 1.70 & 0 \\
UTEO & -1.51 & -2.78 \\
\hline
\end{tabular}

For this purpose, we selected CGPS stations MOCS, MPAA, and MRRA, which were installed after 2004 and are located in the zones where the subsidence is more visible. The MPAA and MRRA show an obvious acceleration in the north and/or east directions (see Fig. 4). The station MOCS also has a small amount of acceleration in the horizontal directions. However, the main displacements are in the vertical directions. In order to tie the PSI results to CGPS data, this study projected the north, east, and vertical directions to the LOS direction (via eq. 1) with directional cosine. Next, the average of PSs displacement rates in the distance of $\mathrm{r}=1,2,4,6$, and $8 \mathrm{~km}$ were examined. In all of the tested CGPS stations, for $r>2 \mathrm{~km}$, the deviation is remarkable, and the stability would be poor. Therefore, we selected the maximum distance from each CGPS station in $\mathrm{r}=2 \mathrm{~km}$. Statistics of the selected PSI

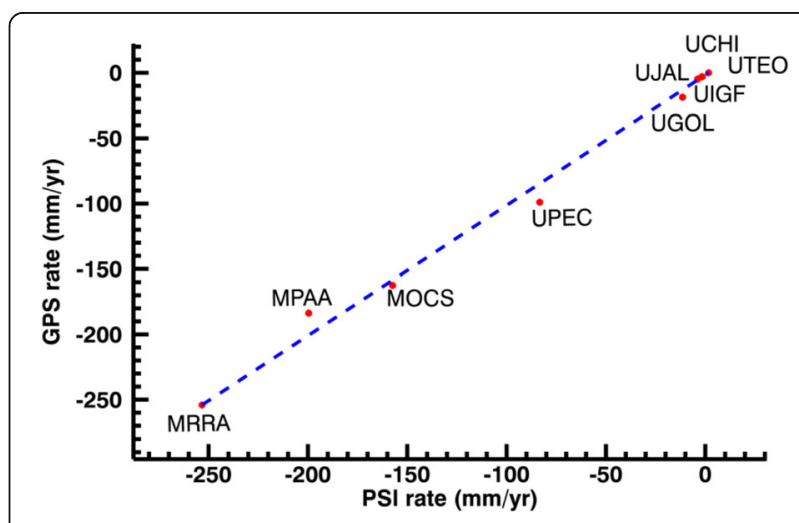

Fig. 10 GPS and PSI comparison in the Mexico City study area from Table 2. The dashed line is 1-to-1 line shows a great correlation between the GPS and PSI data. $R \wedge 2$ is in the range of 0.98 


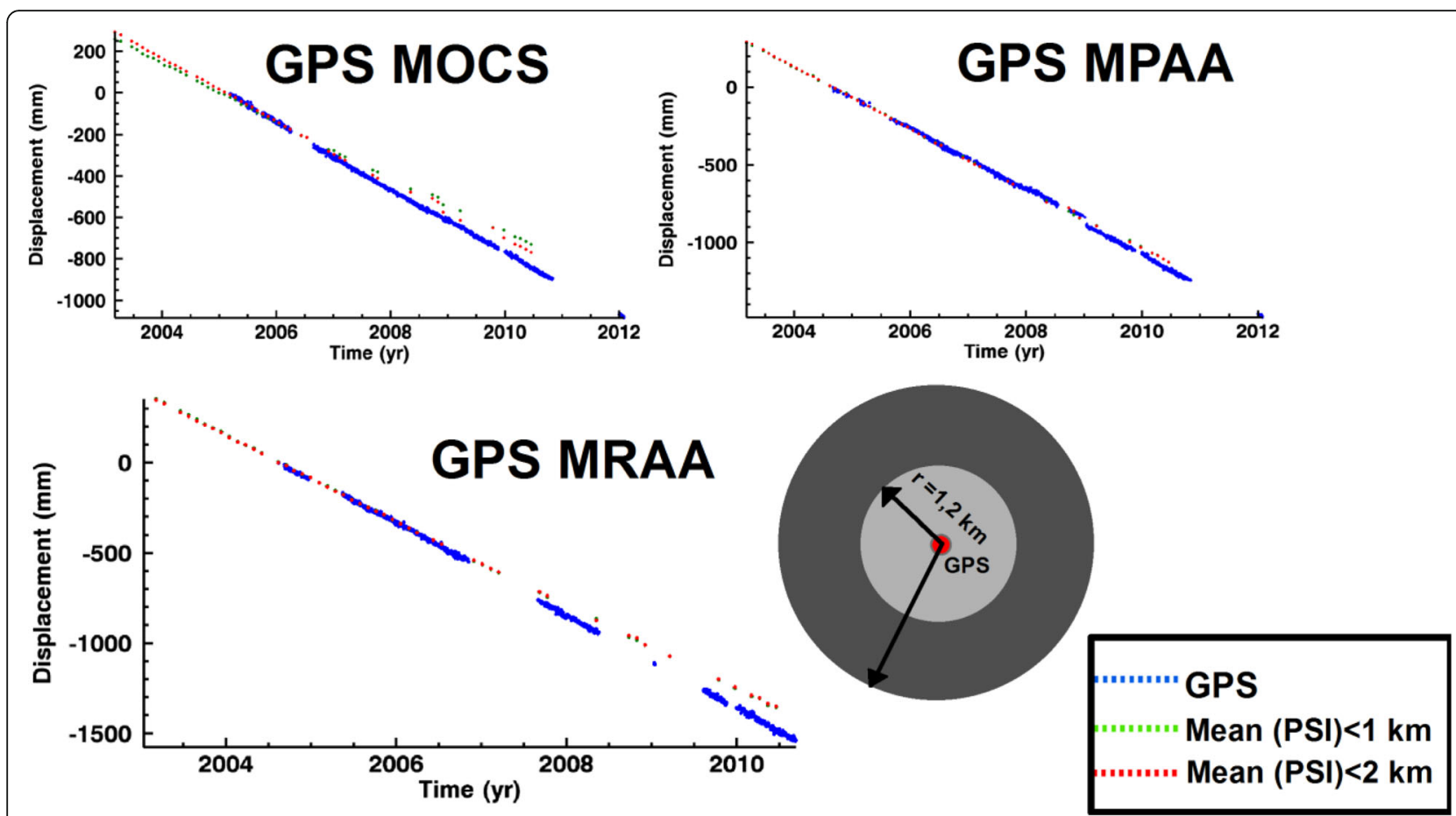

Fig. 11 Comparison of LOS GPS and average of subsets from PSI method

points around the GPS antennas MOCS, MRAA, and MPAA are given in Table 4. This table depicts the number of selected PSs, Min, Max, Mean, and SD for each GPS station.

For three CGPS stations, CGPS data was projected in the LOS direction by Eq. 1. Averaged PSI rate in subsets for $\mathrm{r}=1,2 \mathrm{~km}$ was calculated. As we had seen in the previous sections, for MOCS and MRRA, average PSs rates after $2 \mathrm{~km}$ deviate from CGPS displacement rates. MPPA stays more or less stable to the distance changes (Fig. 12).

For station MPAA, which is the southernmost CGPS station of the three stations above, a perfect correlation has been observed. Until there is a maximum 2-km distance from MPAA, this CGPS station has valid results. A small amount of deviation from this CGPS station after 2009 (June) has been observed. For CGPS stations MOCS and MRAA, the correlations are good until 2007. After 2007, for both stations in $\mathrm{r}=1,2-\mathrm{km}$ small deviations have been observed.

The immediate observations from this analysis are as follows: (a) the slopes for both CGPS and average PSI are similar, lead to the same amount of subsidence rate with two independent methods; and (b) The effective and valid area for each CGPS station is approximately 2 $\mathrm{km}$. In other words, we can trust the GPS and PSI correlation for a circle with a radius of a maximum $2 \mathrm{~km}$.

Risk assessments for existing subsidence in Mexico City The comparison of Mexico City's subsidence monitoring history with the existing research and the current study is depicted in Table 5. This study used larger InSAR and more CGPS temporal baselines in conjunction with the combination of other available remotely-sensed data. We used the SVM classification based on Landsat ETM+ imagery. We applied SVM to analyze the populated area in

Table 4 Statistics of the selected PSI points around the GPS antennas

\begin{tabular}{llllll}
\hline & $\#$ & Min $(\mathbf{m m} / \mathbf{y r})$ & Max $(\mathbf{m m} / \mathbf{y r})$ & MEAN $(\mathbf{m m} / \mathbf{y r})$ & SD $(\mathbf{m m} / \mathbf{y r})$ \\
\hline MOCS $(<1 \mathrm{~km})$ & 739 & -183 & -150 & -155.5 & 9.2 \\
$(<2 \mathrm{~km})$ & 6933 & -233 & -120 & -170.8 & 10.11 \\
MRAA $(<1 \mathrm{~km})$ & 2784 & -286 & -212 & -247.5 & 6.3 \\
$(<2 \mathrm{~km})$ & 10,184 & -299 & -175 & -226 & 9.7 \\
MPAA $(<1 \mathrm{~km})$ & 1230 & -214 & -96 & -152 & 9.11 \\
$(<2 \mathrm{~km})$ & 8298 & -264 & -96 & -174 & 12.3 \\
\hline
\end{tabular}


MOCS

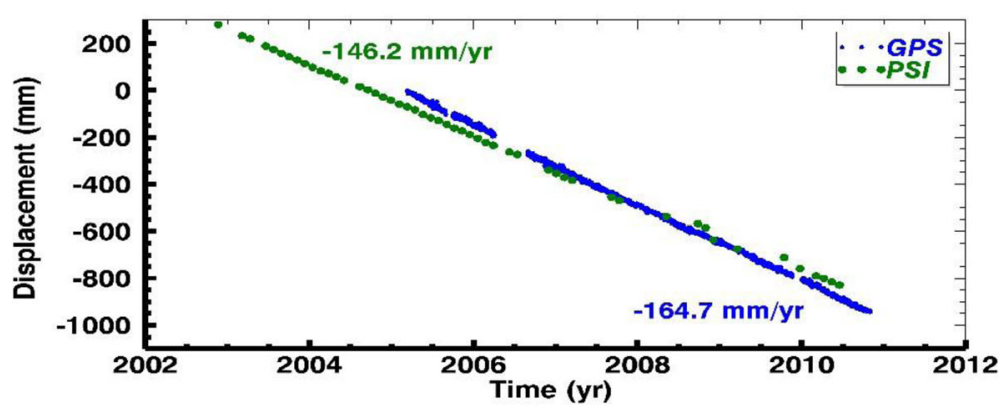

MPAA

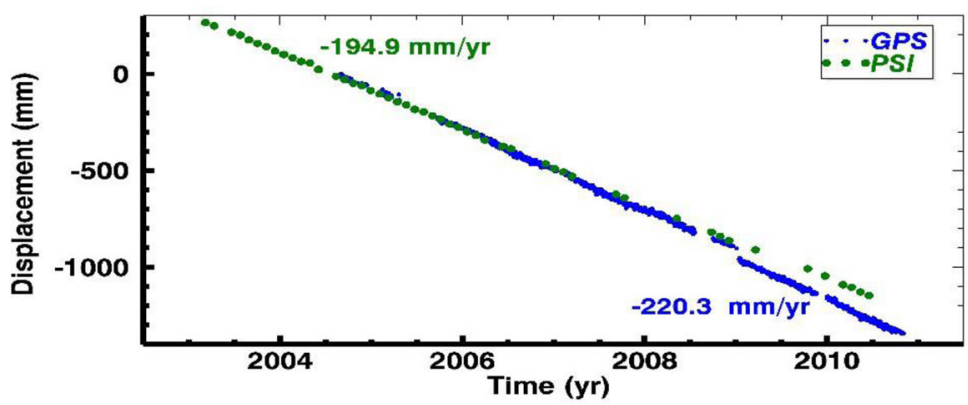

MRRA

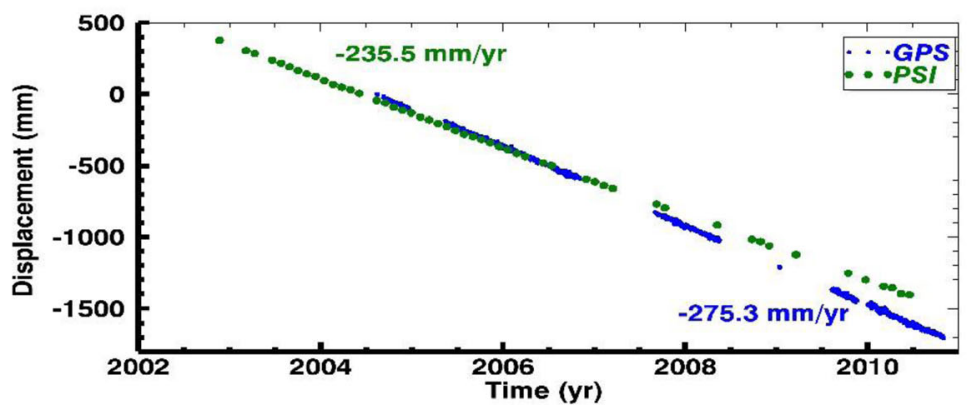

Fig. 12 Comparison of three PSs time series with (vertical) GPS data. For each graph, the closest PS to three GPS stations of MOCS, MPAA, and MRRA (see Fig. 1 for the location of these GPS stations) is given. Deformation rates of each methodology are presented in the corresponding color

Mexico City and compare the subsidence rates from PSI data and risk assessment. The RGB composite (2:3:5) of three available bands was generated, and then we oversampled the composite image with three ROIs. In this last stage, the SVM classifier was applied to the image to obtain the buildings' densities. Figure 7 illustrates three classes of densely populated areas in Mexico City. We overlaid the CGPS stations on the SVM classification map to compare this map with the terrain displacements maps. Comparison with the PSI deformation rates stresses that the denser building zones are located on the highest deformation zones. This comparison also stresses that areas with a high population are at risk for a high degree of subsidence in the eastern and central parts of Mexico City.

In the Mexico City area, the ground deformations are classified into (1) sudden subsidence and (2) slow subsidence. In general, slow subsidence usually causes enormous economic and human-related disasters. Cities built on unconsolidated clays, silts, peats, or sands are in danger of sudden or slow subsidence. Extreme groundwater extractions, flooding, tsunami, and an earthquake have made the morphological settings in Mexico Basin be a dangerous situation of subsidence. In particular, 
Table 5 Mexico City subsidence monitoring history

\begin{tabular}{|c|c|c|c|c|c|}
\hline Researcher(s) & InSAR & GPS & Grace & Maximum rate of subsidence $(\mathrm{mm} / \mathrm{yr})$ & Comparison and Advantages \\
\hline Ortiz-Zamora and Ortega-Guerrero (2010) & - & - & - & 400 & $\begin{array}{l}\text { Ground magnetic survey and lithologic } \\
\text { logs data (1984-1989) }\end{array}$ \\
\hline Ortega-Guerrero et al. (1999) & - & - & - & 400 & $\begin{array}{l}\text { Hydraulic, geotechnical, and historical } \\
\text { data (1984-1989) }\end{array}$ \\
\hline Chaussard et al. (2014) & $x$ & - & - & 300 & InSAR ALOS data (2007-2011) \\
\hline Sowter et al. (2016) & $x$ & - & - & 400 & InSAR Sentinel-1 (2014-2015) \\
\hline Castellazzi et al. (2016a, b) & $x$ & - & $x$ & $250-300$ & $\begin{array}{l}\text { GRACE and InSAR data sets and } \\
\text { SBAS-InSAR algorithm (2007-2011) }\end{array}$ \\
\hline Cabral-Cano et al. (2008) & $x$ & $x$ & - & $300-370$ & $\begin{array}{l}\text { InSAR ERS and ENVISAT } \\
(1996-2003)\end{array}$ \\
\hline Strozzi and Wegmüller (1999) & $x$ & - & - & 400 & $\begin{array}{l}\text { InSAR ERS satellite data sets } \\
(1995-1997)\end{array}$ \\
\hline Osmanoglu et al. (2011) & $x$ & $x$ & - & 300 & $\begin{array}{l}\text { InSAR ENVISAT (2004-2006) } \\
\text { and nine CGPS data sets }\end{array}$ \\
\hline Yan et al. (2012) & $x$ & - & - & 350 & $\begin{array}{l}\text { InSAR ENVISAT (2002-2007), } \\
\text { Gamma-IPTA chain, and SBAS }\end{array}$ \\
\hline Lopez-Quiroz et al. (2009) & $x$ & - & - & 400 & $\begin{array}{l}\text { InSAR ENVISAT images } \\
\text { (2002 and 2007) }\end{array}$ \\
\hline Current study & $x$ & $x$ & - & 352 & $\begin{array}{l}52 \text { ENVISAT images (2002-2010.5), } \\
\text { nine CGPs (1998-2012), and SVM } \\
\text { classification }\end{array}$ \\
\hline
\end{tabular}

buildings and streets add weight to the region and intensify the soil's stress even more. Meanwhile, finding the buildings' extensions and their relationship with ongoing subsidence is crucial.

The existing subsidence due to over-pumping in the Mexico City metropolitan area has been examined in this study. Nelson (2000) showed that a maximum of nine meters of subsidence in an area as large as $225 \mathrm{~km}^{2}$ had been observed in the metropolitan area. As mentioned previously, the main subsidence occurs because of water extraction and the consequent compaction of the alluvial sediments. In the subsiding area, the intergranular pressure of aquifers decreases. The depletion of water at depth is the cause of the observed subsidence. The highest subsidence rate is located in the central and eastern parts of Mexico City. The area experiences rapid subsidence in regions with a subsidence rate greater than $50 \mathrm{~mm} / \mathrm{yr}$ (Fig. 8). It correlates with the regions of intense groundwater extraction, such as Texcoco sediments (Fig. 1) (Osmanoglu et al. 2011). The more stable area is located on the western side of Mexico City (in the mountains). As is evident from a comparison of Figs. 7 and 8, the highest deformation rates are located in the region with high densities of buildings. As the subsidence is developing continually in this region (see GPS results in Fig. 4), the city's central and eastern parts are threatened. With a subsidence rate of $352 \mathrm{~mm} / \mathrm{yr}$, there will be a total of $3.5 \mathrm{~m}$ of displacement in ten years. In this case, floods in rainy seasons will be of great concern in these two parts of the city. However, this may be an inaccurate estimation. Because the compaction of aquifers in response to water extraction depends on the aquifers' physical properties, subsidence may slow down over time (Terzaghi 1925). With more than $2500 \mathrm{~m}$ of sediments in the Mexico Basin, estimating the stopping point of subsidence is difficult (Jose and Sanchez, 1989; Scharroo and Visser 1998). We need additional subsurface data for more accurate estimations analysis. The weak subsoil, which is mostly made up of elasto-plastic clays minerals, has the capacity for instantaneous and high compressions.

Meanwhile, exceeding water withdrawal results have made the Mexico City area susceptible to any geohazard threats. For instance, in 1985, at least 40,000 people died in an $\mathrm{M} 8.1$ earthquake $\left(18.2^{\circ} \mathrm{N}, 102.7^{\circ} \mathrm{W}\right)$ with an epicentre $350 \mathrm{~km}$ away from Mexico City. The damage was directly related to amplification phenomena due to local stratigraphic settings, and the central part of Mexico City suffered an average vertical displacement of $30 \mathrm{~cm}$ (Murillo and Manuel 1995). Economically, the subsidence costs are enormous and include more than three billion USD due to the immediate collapse of 412 buildings and the severe damage of another 3124 buildings (Murillo and Manuel 1995). Maintenance and geotechnical supports have indirectly led to an increase in flood risk, soil fractures, and other threats to human life. As these costs grow over time, it becomes increasingly important to assess potential damage's extension and magnitude. Meanwhile, the monitoring of subsidence must be continued with more GPS stations. As well, a new 
generation of InSAR satellites such as Sentinel, TerraSAR-X, and CosmoSkyMed is essential.

\section{Conclusion}

By comparing Mexico City's subsidence monitoring history (Table 5) with existing research and the current study, this study focused on the use of larger InSAR temporal baselines and more CGPS temporal baselines. We concluded that the combination of InSAR and CGPS temporal baselines with other available remotely sensed data utilizing SVM could improve our understanding of subsidence visualization. Coupling GPS, InSAR, and optical remotely-sensed analysis could lead to the accurate monitoring of subsidence in the area of Mexico City by exploiting the strengths and minimizing the weaknesses of each technique

The proper low spatial resolution CGPS stations (only nine stations) with east, north, and vertical components are used to calibrate the field observation assessment of the high spatial resolution PS displacement rates (more than 600,000 points). This study concluded a good correlation between CGPS and PSI data. PSI is a relative method by nature despite CGPS methodology, which provides absolute displacement rates. This is why we combined PSI with CGPS stations.

This study combined InSAR, CGPS, and optical remotely-sensed imageries to measure Mexico City's subsidence because of groundwater extraction and related risk assessments. Fifty-two ENVSAT-ASAR imageries and nine CGPS stations are used to study the deformations. Geodetic analyses based on InSAR and GPS methodologies give promising results for monitoring deformation rates in large areas. Long-term deformation rates based on PSI and GPS methodologies are similar to those found in previous InSAR and PSI works. The subsidence in the eastern part of the Mexico City metropolitan area shows fast and constant rates. This study concluded that the maximum subsidence rate is $352 \mathrm{~mm} /$ year in the LOS direction. This subsidence rate is occurring in the central and eastern parts of Mexico City. The InSAR/PSI analysis results show almost perfect agreement with the GPS data at R2 in the order of 0.98 in most of the CGPS stations.

A negligible amount of observed seasonal variations in the Vertical component of CGPS stations and PSI time series leads to the conclusion that aquifers' recharge in the rainy seasons is small (withdrawal over recharge). The fast subsidence rates in the Mexico City metropolitan area result from a massive amount of well pumping. The consequence of this is clay-rich aquifers' compactions and the permanent loss of porosity and reservoir capacity. The data we used in this study show that the mitigations have no effect on the long-term compaction of the clay-rich aquifers, and the seasonal variations are small. The data also show that there is a considerable amount of risk in the metropolitan area of Mexico City. The subsidence (see Table 5) leads to the damage of buildings and infrastructures as well as economic ramifications.

This study used SVM classification to classify the populated area and find its correlation with the high PSI deformation rates. The maximum amount of subsidence is occurring in the highly populated zone of the Mexico City metropolitan area. PSI and SVM are two valuable methods to study these kinds of subsidence threats in the metropolitan areas.

Following a further assessment of subsidence, mechanism of alluvial compaction, change of porosity and permeability, and geohazards, this study suggests that additional geophysical work is needed to map the subsidence's exact extension and subsurface geology. Geodetic surveys using denser CGPS networks could estimate the precise amount of subsidence and its extensions. Regarding InSAR and PSI, using the new and improved generation of InSAR images such as TerraSAR-X and CosmoSkyMed imageries could provide more information about the existing subsidence.

\section{Supplementary Information}

The online version contains supplementary material available at https://doi. org/10.1186/s40677-021-00179-x.

\section{Additional file 1:}

\section{Acknowledgments}

The authors thank ESA for providing the download of the ENVISAT-ASAR images from ESA's virtual web page (http://eo-virtual-archive4.esa.int/). We also appreciate NASA for providing the download of Landsat ETM+ imageries from the Global Land Cover Facility (GLCF) web page (http://www. glcf.umd.edu). This material is partly based on GPS data provided by the Trans-boundary, Land and Atmosphere Long-term Observational and Collaborative Network (TLALOCNet) operated by the Servicio de Geodesia Satelital (SGS) at the Instituto de Geofísica-Universidad Nacional Autónoma de México (UNAM) and UNAVCO Inc. TLALOCNet is supported by the National Science Foundation agreements EAR-1338091 and EAR-1724794; CONACyT projects 253760, 256012, and 2017-01-5955; UNAM-PAPIIT projects IN104213, IN109315-3, IN104818-3, IV100215, and IN111509; NASA-ROSES NNX12AQ08G; and supplemental support from UNAM-Instituto de Geofísica. We gratefully acknowledge Luis Salazar-Tlaczani at the SGS for station maintenance and field support for this network. In addition, we appreciate the research unit of the Southwest Jiaotong University (SWJTU) for the GeoAI Smarter Map and LiDAR Lab startup funding support.

\section{Authors' contributions}

Conceptualization: Davod Poreh; Data curation: Davod Poreh and Enrique Cabral-Cano; Formal analysis: Davod Poreh; Funding acquisition: Saied Pirasteh; Investigation: Davod Poreh, Saied Pirasteh, and Enrique Cabral-Cano; Methodology: Davod Poreh and Saied Pirasteh; Project administration: Saied Pirasteh and Enrique Cabral-Cano; Resources: Davod Poreh and Saied Pirasteh; Software: Davod Poreh and Saied Pirasteh; Supervision: Saied Pirasteh; Validation: Davod Poreh and Saied Pirasteh; Visualization: Davod Poreh, Saied Pirasteh, and Enrique Cabral-Cano; Writing of original draft: Davod Poreh and Saied Pirasteh; Writing, reviewing, and editing: Davod Poreh, Saied Pirasteh, and Enrique Cabral-Cano. The author(s) read and approved the final manuscript. 


\section{Funding}

This research received funds for publication from the Faculty of Geosciences and Environmental Engineering (FGEE), Southwest Jiaotong University (SWJTU), China.

\section{Availability of data and materials}

All data are available upon request.

\section{Declarations}

\section{Submission declaration and verification}

This research work has not been published previously nor is it under consideration for publication elsewhere.

\section{Competing interests}

The authors declare no conflict of interest.

\section{Author details}

'Dipartimento di Ingegneria Elettrica edelle Tecnologie dell'Informazione, Universita degli Studi di, Napoli Federico II, Via Claudio, 21, 80125 Naples, Italy. ${ }^{2}$ Department of Surveying and Geoinformatics, Faculty of Geosciences and Environmental Engineering (FGEE), Southwest Jiaotong University, Chengdu 611756, China. ${ }^{3}$ Departamento de Geomagnetismo Expiración, Instituto de Geofísica, Universidad Nacional, Autónoma de México, Ciudad Universitaria, 04510 México D.F, Mexico.

\section{Received: 27 March 2020 Accepted: 25 February 2021}

\section{Published online: 05 March 2021}

\section{References}

Albano M, Polcari M, Bignami C, Moro M, Saroli M, Stramondo S (2016a) An innovative procedure for monitoring the change in soil seismic response by InSAR data: application to the Mexico City subsidence. Int J Appl Earth Obs Geoinf 53:146-158

Albano M, Polcari M, Bignami C, Moro M, Saroli M, Stramondo S (2016b) An innovative procedure for monitoring the change in soil seismic response by InSAR data: application to the Mexico City subsidence. Int J Appl Earth Obs Geoinf 53:146-158

Altamimi Z, Sillard P, Boucher C (2002) ITRF2000: A new release of the international terrestrial reference frame for Earth science applications. J Geophys Res (Solid Earth) 107j(1):2-19 [Online]. Available: http://adsabs.harva rd.edu/abs/2002JGRB.107j.ETG2A

Arce JL, Layer PW, Lassiter J, Benowitz JA, Macías JL, Ramírez-Espinosa J (2013) $40 \mathrm{Ar} / 39 \mathrm{Ar}$ dating, geochemistry, and isotopic analyses of the Quaternary Chichinautzin Volcanic Field, south of Mexico City: implications for timing, effusion rate, and distribution of the volcanism. Bull Volcanol 75:774. https:// doi.org/10.1007/s00445-013-0774-6

Argus DF (2007) Defining the translational velocity of the reference frame of Earth. Geophys J Int 169(3):830-838, [Online]. Available. https://doi.org/1 $0.1111 / j .1365-246 X .2007 .03344 . x$

Ayazi MH, Pirasteh S, Pradhan B, Mahmoodzadeh A (2010) Disasters and risk reduction in groundwater: Zagros Mountain, Southwest Iran using geoinformatics techniques. Disaster Advances 3(1):51-57

Bell J, Amelung F, Ramelli A, Blewitt G (2002) Land subsidence in Las Vegas, Nevada, 1935-2000: new geodetic data show evolution, revised spatial patterns, and reduced rates. Environ Eng Geosci 8(3):155-174

Berardino P, Fornaro G, Lanari R, Sansosti E (2002) A new algorithm for surface deformation monitoring based on small baseline differential SAR interferograms. IEEE Trans Geosci Remote Sens 40:2375-2383

Cabral-Cano E, Dixon TH, Miralles-Wilhelm F, Diaz-Molina O, Sanchez-Zamora O, Carande RE (2008) Space geodetic imaging of rapid ground subsidence in Mexico City. Geological Soc Am Bull 120(11-12):1556-1566 [Online]. Available: http://gsabulletin.gsapubs.org/cgi/content/abstract/120/11-12/1556

Carrillo, N. 1947. Influence of artesian wells in the sinking of Mexico City, Secretaria de Hacienda y Credito Publico, Mecico City, 47(11):7-14

Castellazzi P, Arroyo-Domínguez N, Martel R, Calderhead Al, Normand JC, Gárfias J, Rivera A (2016a) Land subsidence in major cities of Central Mexico: Interpreting InSAR-derived land subsidence mapping with hydrogeological data. Int J Appl Earth Obs Geoinf 47:102-111

Castellazzi P, Martel R, Rivera A, Huang J, Pavlic G, Calderhead Al, Chaussard E, Garfias J, Salas J (2016b) Groundwater depletion in Central Mexico: use of
GRACE and InSAR to support water resources management. Water Resour Res 52:5985-6003

Chaussard E, Wdowinski S, Cabral-Cano E, Amelung F (2014) Land subsidence in central Mexico detected by ALOS InSAR time-series. Remote Sens of Environ 140:94-106. https://doi.org/10.1016/j.rse.2013.08.038

Cigna F, Tapete D, Garduño-Monroy VH, Muñiz-Jauregui JA, García-Hernández $\mathrm{OH}$, Jiménez-Haro A (2019a) Wide-area InSAR survey of surface deformation in urban areas and geothermal fields in the eastern trans-Mexican Volcanic Belt, Mexico. Remote Sens 11(20):2341

Cigna F, Tapete D, Garduño-Monroy VH, Muñiz-Jauregui JA, García-Hernández $\mathrm{OH}$, Jiménez-Haro A (2019b) Wide-area InSAR survey of surface deformation in urban areas and geothermal fields in the eastern trans-Mexican Volcanic Belt, Mexico. Remote Sens 11(20):2341

Crosetto M, Biescas E, Duro J, Closa J, Arnaud A (2008) Generation of advanced ERS and ENVISAT interferometric SAR products using the stable point network technique. Photogramm Eng Remote Sens 74:443-450

Crosetto M, Crippa B, Biescas E (2005) Early detection and in depth analysis of deformation phenomena by radar interferometry. Eng Geol 79:81-91

Cuevas J (2004) Foundation conditions in Mexico City. In: Inter Conf Soil Mech 1936, Vol. 3. GODF, Normas t'ecnicas complementarias para dise no y construcci'on de cimentaciones

Dai K, Li Z, Tomás R, Liu G, Yu B, Wang X, Cheng H, Chen J, Stockamp J (2016) Monitoring activity at the Daguangbao mega-landslide (China) using Sentinel-1 TOPS time series interferometry. Remote Sens Environ 186:501513

Del Soldato M, Farolfi G, Rosi A, Raspini F, Casagli N (2018) Subsidence evolution of the Firenze-Prato-Pistoia plain (Central Italy) combining PSI and GNSS data. Remote Sens 10(7):1146

Dixon TH, Miller M, Farina F, Wang H, Johnson D (2000) Present-day motion of the Sierra Nevada block and some tectonic implications for the basin and range province. North Am Cordillera Tectonics 19:1-24 [online]. Available: http://www.agu.org/pubs/crossref/2000/1998TC001088.shtml

Du Z, Ge L, Ng AHM (2019) Insar reveals the long term subsidence and potential land degradation in Mexico City from 2004 to 2018 with five SAR sensors. In: IGARSS 2019-2019 IEEE International Geoscience and Remote Sensing Symposium, pp 421-424

Farolfi G, Del Soldato M, Bianchini S, Casagli N (2019) A procedure to use GNSS data to calibrate satellite PSI data for the study of subsidence: an example from the north-western Adriatic coast (Italy). Eur J Remote Sensing 52(sup4): 54-63

Ferrari L, López-Martínez M, Aguirre-Díaz G, Carrasco-Núñez G (1999) Space-time patterns of Cenozoic arc volcanism in Central Mexico: from Sierra Madre occidental to the Mexican Volcanic Belt. Geology 27:303-306

Ferretti A, Fumagalli A, Novali F, Prati R, C. F. and Rucci, A. (2011a) A new algorithm for processing interferometric data-stacks: SqueeSAR. IEEE Trans Geosci Remote Sens 49:3460-3470

Ferretti A, Prati C, Rocca F (1999) Multibaseline InSAR DEM reconstruction: the wavelet approach. IEEE Trans Geosci Remote Sens 37(2):705-715

Ferretti A, Prati C, Rocca F (2011b) Permanent scatterers in SAR interferometry. IEEE Trans Geosci Remote Sens 39(1):8-20

Gourmelen N, Amelung F, Casu F, Manzo M, Lanari R (2007) Mining-related ground deformation in Crescent Valley, Nevada. Implications Sparse GPS Networks Geophys Res Letters 34:9309

Hanssen R, Bamler R (1999) Evaluation of interpolation kernels for SAR interferometry. IEEE Trans Geosci Remote Sens 37:318-321

Hanssen RF (2001) Radar interferometry: data interpretation and error analysis. Kluwer Academic, Dordrecht

Hilley GE, Bürgmann R, Ferretti A, Novali F, Rocca F (2004) Dynamics of slowmoving landslides from permanent scatterers. Science 304:1952-1955

Hooper A (2008) A multi-temporal InSAR method incorporating both persistent scatterer and small baseline approaches. Geophys Res Lett 35:L16302

Jose R, Sanchez P (1989) Geology and tectonics of the basin of Mexico and their relationship with the damage caused by the earthquakes of September 1985. Int J Mining Geological Eng 7(1):17-28

Kampes B (2005) Displacement parameter estimation using permanent scatterer interferometry, Ph.D. thesis, Technische Universiteit Delft

Lanari R, Lundgren P, Manzo M, Casu F (2004) Satellite radar interferometry time series analysis of surface deformation for Los Angeles, California. Geophys Res Letter 31:23613

Lopez-Quiroz DP, Tupin F, Briole P, Nicolas J (2009) Time series analysis of Mexico City subcidence constrained by radar interferometry. J Appl Geophys 69(1):1-15 
López-Quiroz P, Doin M, Tupin F, Briole P, Nicolas J (2009) Time series analysis of Mexico City subsidence constrained by radar interferometry. J Appl Geophys 69(1):1-15

Mora O, Mallorqui JJ, Broquetas A (2003) Linear and nonlinear terrain deformation maps from a reduced set of interferometric SAR images. IEEE Trans Geosci Remote Sens 41:2243-2253

Murillo M, Manuel J (1995) The 1985 Mexico earthquake. Geofisica Coumbia (Universidad Nacional de Colombia) 3:5-19

Navarro-Sanchez VD, Lopez-Sanchez JM (2013) Spatial adaptive speckle filtering driven by temporal polarimetric statistics and its application to PSI. IEEE Trans Geosci Remote Sens 99:1-10

Nelson SA (2000) Subsidence: Dissolution and human-related causes, Natural Disasters, pp 2-10 [Online]. Available: https://www.tulane.edu/ sanelson/Na tural_Disasters/subsidence.pdf

Ortega-Guerrero A, Cherry JA, Rudolph DL (1993) Large-scale aquitard consolidation near Mexico City. Ground Water 31(5):708-718. [online]. Available. https://doi.org/10.1111/j.1745-6584.1993.tb00841.x

Ortega-Guerrero A, Rudolph DL, Cherry JA (1999) Analysis of long-term land subsidence near Mexico City: field investigations and predictive modeling Water Resour Res 35(11):3327-3341

Ortiz-Zamora D, Ortega-Guerrero A (2010) Evolution of long-term land subsidence near Mexico City: Review, field investigations, and predictive simulations. Water Resources Res 46:W01513

Osmanoglu B, Dixon HT, Wdowinski S, Cabral-Cano E, Jiang Y (2011) Mexico City subsidence observed with persistent scatterer InSAR. Int J Appl Earth Obs Geoinf 13(1):1-12

Pepe A, Berardino P, Bonano M, Euillades LD, Lanari R, Sansosti E (2011) SBASbased satellite orbit correction for the generation of DInSAR time-series: application to RADARSAT-1 data. IEEE Trans Geosci Remote Sens 49:51505165

Perissin D, Wang T (2012) Repeat-pass SAR interferometry with partially coherent targets. IEEE Trans Geosci Remote Sens 50(1):271-280

Poreh D, lodice A, Riccio D, Ruello G (2017) Railways' stability observed in Campania (Italy) by InSAR data. Eur J Remote Sensing 49(1):417-431

Poreh D, Pirasteh S (2020) InSAR observations of the Medicina geodetic observatory and CosmoSkyMed images analysis, natural hazards, https://rdcu. be/b5jgG. https://doi.org/10.1007/s1 1069-020-04123-4

Rodell M, Velicogna I, Famiglietti JS (2009) Satellite-based estimates of groundwater depletion in India. Nature 460(7258):999-1002

Rudolph DL, Sultan R, Garfias J, McLaren RG (2006) Significance of enhanced infiltration due to groundwater extraction on the disappearance of a headwater lagoon system: Toluca Basin, Mexico. Hydrogeol J 14(1-2):115130

Saleh M, Becker M (2019) New estimation of Nile Delta subsidence rates from InSAR and GPS analysis. Environ Earth Sci 78(1):6

Salvi S, Atzori S, Tolomei C, Allievi J, Ferretti A, Rocca F, Prati C, Stramondo S, Feuillet N (2004) Inflation rate of the Colli Albani volcanic complex retrieved by the permanent scatterers SAR interferometry technique. Geophys Res Lett 31:L12606

Scharroo R, Visser P (1998) Precise orbit determination and gravity field improvement for the ERS satellites. J Geophys Res 103(C4):8113-8127

Sella GF, Dixon TH, Mao A (2002) REVEL: A model for recent plate velocities from space geodesy. J Geophys Res 107;B4:2081. https://doi.org/10.1029/2 000JB000033

Sowter A, Amata MBC, Cigna F, Marsha S, Athaba A, Alshammari L (2016) Mexico City land subsidence in 2014-2015 with Sentinel-1 IW TOPS: results using the intermittent SBAS (ISBAS) technique. Int J Appl Earth Obs Geoinf 52:230-242

Strozzi T, Wegmüller U (1999) Land subsidence in Mexico City mapped by ERS differential SAR interferometry. In: Geoscience and Remote Sensing Symposium, 28 June-2 July 1999, pp 4:1940-4:1942

Suárez G, Jaramillo SH, López-Quiroz P, Sánchez-Zamora O (2018) Estimation of ground subsidence in the city of Morelia, Mexico using satellite interferometry (INSAR), S. Geofis Int 57(1):39-58

Terzaghi K (1925) Principles of soil mechanics: IV: Settlement and consolidation of clay. Eng News Rec 95(3):874-878

Usai S, Hanssen R (1997) Long time scale INSAR by means of high coherence features. In: Third ERS symposium|space at the service of our environment, pp 225-228

Wang X, Liu G, Yu B, Dai K, Zhang R, Li Z (2010) 3D coseismic deformations and source parameters of the 2010 Yushu earthquake (China) inferred from DInSAR and multiple-aperture InSAR measurements. Remote Sens Environ 152:174-189
Yan Y, Doin MP, L'opez-Quiroz P, Tupin F, Fruneau B, Pinel V, Trouv'e E (2012) Mexico City subsidence measured by InSAR time series: joint analysis using PS and SBAS approaches. IEEE J Selected Topic Appl Earth Observation Remote Sensing 5(4):1312-1326

Zebker HA, Rosen PA, Hensley S (1997) Atmospheric effects in interferometric synthetic aperture radar surface deformation and topographic maps. J Geophys Res 102(B4):7547-7563

Ziwen Z, Liu Y, Li F, Li Q, Ye W (2019) Land subsidence monitoring based on InSAR and inversion of aquifer parameters. EURASIP J Wirel Commun Netw 2019(1):1-18

\section{Publisher's Note}

Springer Nature remains neutral with regard to jurisdictional claims in published maps and institutional affiliations.

\section{Submit your manuscript to a SpringerOpen ${ }^{\circ}$ journal and benefit from:}

- Convenient online submission

- Rigorous peer review

- Open access: articles freely available online

- High visibility within the field

- Retaining the copyright to your article

Submit your next manuscript at $\boldsymbol{\nabla}$ springeropen.com 